Portland State University

PDXScholar

\title{
A Comparison of Parent Interview and Direct Assessment of Receptive Language in Preschool- aged Children with Cerebral Palsy
}

Susan Kathleen Livick

Portland State University

Follow this and additional works at: https://pdxscholar.library.pdx.edu/open_access_etds

Part of the Speech and Rhetorical Studies Commons

Let us know how access to this document benefits you.

\section{Recommended Citation}

Livick, Susan Kathleen, "A Comparison of Parent Interview and Direct Assessment of Receptive Language in Preschool-aged Children with Cerebral Palsy" (1997). Dissertations and Theses. Paper 5327.

https://doi.org/10.15760/etd.7200

This Thesis is brought to you for free and open access. It has been accepted for inclusion in Dissertations and Theses by an authorized administrator of PDXScholar. Please contact us if we can make this document more accessible: pdxscholar@pdx.edu. 


\section{THESIS APPROVAL}

The abstract and thesis of Susan Kathleen Livick for the Master of Science in Speech Communication: Speech and Hearing Sciences were presented on June 2, 1997, and accepted by the thesis committee and the department.

COMMITTEE APPROVALS:

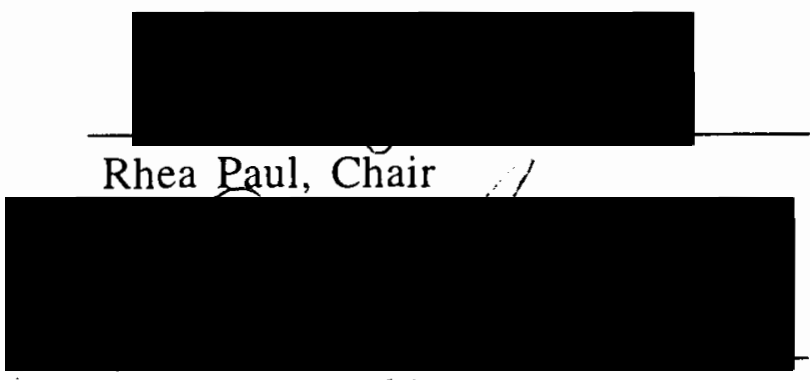

John Tetnowski

DEPARTMENT APPROVAL:

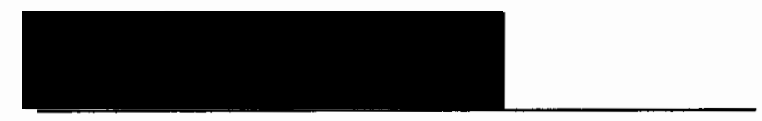

Carol Mack

Representative of the Office of Graduate Studies

$* * * * * * * * * * * * * * * * * * * * * * * * * * * * * * * * * * * * * * * * * * * * * * * * * * * * * * * * * * * * * * * * * * *$

ACCEPTED FOR PORTLAND STATE UNIVERSITY BY THE LIBRARY by

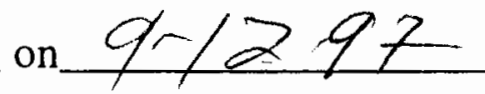




\begin{abstract}
An abstract of the thesis of Susan Kathleen Livick for the Master of Science in Speech Communication: Speech and Hearing Sciences presented on June 2, 1997.
\end{abstract}

Title: A Comparison of Parent Interview and Direct Assessment of Receptive Language in Preschool-Aged Children with Cerebral Palsy.

Cerebral palsy is a multiply handicapping condition which may affect motor skills, hearing, sight, speech and cognitive functioning. Assessment instruments which do not rely on an intact sensory and motor system are needed for use with the population with cerebral palsy in order to obtain valid information regarding levels of functioning. The information obtained from the results of modified assessment instruments can be used to plan and implement intervention at the child's current level of functioning.

The purpose of the present study was to determine whether or not parent interview/report is a reliable means of assessing receptive communication skills in preschool-aged children with cerebral palsy. Additionally, the relationship between motor skills and receptive language skills in terms of 
severity of motor impairment was examined.

The subject pool was comprised of fifteen children, 10 males and 5 females, between the ages of three to six years who were participating in a longitudinal study at Portland State University. Each subject and his/her mother participated in a two and a half hour in-home assessment session. A physical therapy student accompanied this examiner to the subject's homes in order to address positioning needs before the direct measure was administered. Both the Vineland Adaptive Behavior Scale - Interview Format and the Peabody Picture Vocabulary Test - Revised were administered to each participating subject.

A Spearman correlation coefficient was performed in order to examine the strength of the relationship between parent report/interview and direct assessment. A significance value of .05 was used. Results revealed that parent report is a valid means for assessing receptive communication skills in the preschool-aged population with cerebral palsy. Two one-way measures of analysis of variance (ANOVA) were performed in order to examine whether or not a significant difference existed, among the categories of motor impairment in terms of receptive 
communication and receptive vocabulary scores. Significant differences were not found for the development of receptive language skills between the categories of motor impairment in this sample. However, further research using a larger sample size may identify significant differences between the moderate and severe groups in terms of scores obtained on the PPVT and the VABS receptive subscale. 
A COMPARISON OF PARENT INTERVIEW AND DIRECT

ASSESSMENT OF RECEPTIVE LANGUAGE

IN PRESCHOOL-AGED CHILDREN

WITH CEREBRAL PALSY

b y

SUSAN KATHLEEN LIVICK

A thesis submitted in partial fulfillment of the requirements for the degree of

\author{
MASTER OF SCIENCE \\ in \\ SPEECH COMMUNICATION: \\ SPEECH AND HEARING SCIENCES
}

\author{
Portland State University \\ 1997
}




\section{ACKNOWLEDGEMENTS}

I wish to express my appreciation to a number of individuals who have been invaluable to me throughout my graduate program.

Dr. Rhea Paul, for without her guidance, support and encouragement this study would not have been possible. Her enthusiasm for research along with the establishment of graduate research assistant positions have allowed me to experience speech and language pathology in a broader sense.

A special thanks to Dr. John Tetnowski for his dedication to all students and for his ongoing and never ending assistance in the planning of the last three years of my college career.

I would also like to thank all the families who opened up their homes and busy schedules to participate in the study.

My mother and father are graciously appreciated, for without their loving guidance and inspiration I would not be the woman I am today.

Finally, an enormous debt of gratitude is owed to my husband, Jeff, whose positive outlook on life, sense of humor, and emotional support assisted me throughout the tribulation of extended education. 


\section{TABLE OF CONTENTS}

PAGE

ACKNOWLEDGEMENTS ........................................................ iii

LIST OF TABLES …............................................................. vi

\section{CHAPTER}

I INTRODUCTION AND STATEMENT OF PURPOSE

Introduction

Statement of Purpose $\ldots \ldots \ldots \ldots \ldots \ldots \ldots \ldots \ldots \ldots \ldots . . . \quad 3$

Definition of Terms

I I $\quad$ REVIEW OF THE LITERATURE ......................... 6

Definition, Classification, Topography

and Severity of Cerebral Palsy ............ 6

Perceptual-Motor, Cognitive and

Communication Impairments in Cerebral Palsy .................................... 11

Difficulties in the Assessment of Individuals with Cerebral Palsy and Potential Solutions ........................ 20

II I METHODS AND PROCEDURES …......................... 26

Subjects (................................................... 26

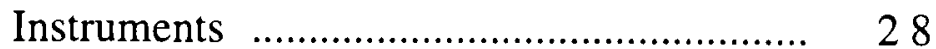


Reliability

Statistical Analysis

IV RESULTS AND DISCUSSION

Results

40

Discussion

46

V SUMMARY AND IMPLICATIONS

48

Summary

48

Clinical Implications

Research Implications

REFERENCES

APPENDICES

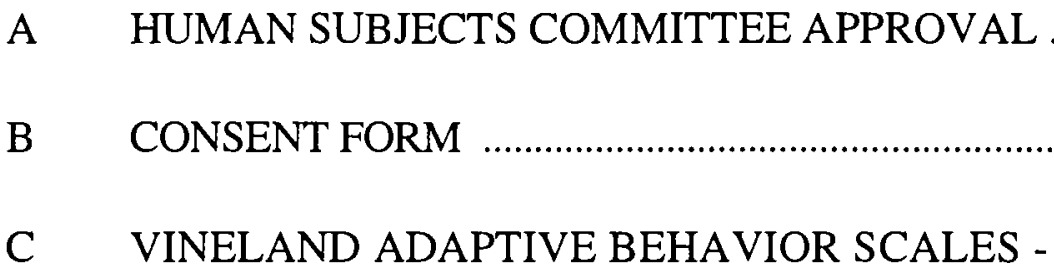 INTERVIEW EDITION

56

57

D PEABODY PICTURE VOCABULARY TEST REVISED, FORM - L

E PEABODY PICTURE VOCABULARY TEST REVISED SIZE MODIFICATIONS

F RAW DATA TABLE 76 


\section{LIST OF TABLES}

TABLE

PAGE

1

Summary of Subjects

27

2

Modifications to Vineland Questions

35

3

ANOVA Models to be Used in Analysis

39

4

Group Descriptive Statistics and

Standard Scores

42

5 Group Descriptive Statistics and

Age Equivalents 
CHAPTER I

INTRODUCTION AND STATEMENT OF PURPOSE

\section{INTRODUCTION}

Cerebral palsy is a multiply handicapping condition caused by brain damage occurring before, during, or shortly after birth and characterized by motor dysfunction and a variety of associated problems (McDonald, p. 3). Cerebral palsy not only affects motor skills but may also involve impairments of hearing, sight, speech, and cognitive functioning. Degrees of involvement in each area of impairment can range from minimal to severe. Thus, no typical profile of functioning exists amongst this population (Parker, 1987).

Valid assessment of language skills in nonvocal, physically disabled individuals has been an ongoing challenge for many professionals. Most assessment instruments rely on an intact sensory and motor system, allowing the individual to manipulate objects and speak intelligibly. In 1975, with the passage of Public Law 94-142, the Education of All Handicapped Children act, professionals became obligated to provide nondiscriminatory assessments that made provisions for the response limitations of this population (Johnson-Martin, Wolters, \& Stowers, 1987). 
Reported assessment results are used to (1) provide access to services, (2) to determine the most appropriate learning environments and educational programs, and (3) to develop effective augmentative communication systems (Johnson-Martin, Wolters, \& Stowers, 1987).

Invalid assessment techniques and results regarding levels of functioning can effect the nonvocal, physically handicapped child in a variety of ways. Parents and teachers are influenced by reported scores and may fashion the environment based on their beliefs about the child's capacities for learning. Expectations may be lowered in terms of linguistic, social, and developmental demands made on the child to be an active participant in his/her environment (Johnson-Martin, Wolters, \& Stowers, 1987). Furthermore, the type of classroom placement, whether academically-based or one which focuses upon functional living skills, is determined by reported levels of functioning. These administrative decisions, based on invalid test results, can effect the quality of stimulation and education the child will receive throughout their entire school experience (Johnson-Martin, Wolters, \& Stowers, 1987). 
STATEMENT OF PURPOSE

The purpose of this study was to address the language assessment difficulties posed by this population in terms of validity of parent interview/report vs. direct assessment. Additionally, the relationship between the varying degrees of motor impairment and the development of receptive communication and receptive vocabulary was examined. The following questions were addressed in the study:

1. Is there a significant relationship between the receptive communication age equivalent obtained through parent interview (VABS) and the receptive vocabulary age equivalent obtained through direct assessment (PPVT-R)?

2. Is there a significant relationship between the motor skills age equivalent and the receptive communication age equivalent, both obtained through parent interview (VABS)?

3. Is there a significant relationship between the motor skills standard score obtained through parent interview (VABS) and the receptive vocabulary standard score obtained through direct assessment (PPVT-R)?

4. Are there significant differences among the different diagnostic categories of motor impairment in terms of the receptive communication (VABS) and receptive vocabulary (PPVT-R) developmental quotients? 
The null hypothesis for question one states that there will be no significant correlation between the receptive communication age equivalent and the receptive vocabulary age equivalent.

The null hypothesis for question two states that there will be no significant correlation between the motor skills age equivalent and the receptive communication age equivalent.

The null hypothesis for question three states that there will be no significant relationship between the motor skills standard score and the receptive vocabulary standard score.

The null hypothesis for question four states that there are no significant differences between the diagnostic categories of motor impairment in terms of receptive communication and receptive vocabulary developmental quotients.

\section{DEFINITION OF TERMS}

The following are descriptions of specific terms used in this study.

Cerebral Palsy: A multiply handicapping condition caused by brain abnormality resulting from maldevelopment or damage occurring before, during, or shortly after birth and characterized by motor dysfunction and a variety of associated problems (McDonald, p. 3). 
Cognition: The process or processes by which an organism gains knowledge of or becomes aware of events or objects in its environment (Bloom \& Lazerson, p. 353).

Expressive Language: A coded system of communication that uses the modalities of speaking, writing, and signing (Bloom \& Lazerson, p. 353).

Fine Motor Skills: How the individual uses hands and fingers to manipulate objects (Sparrow, Balla, \& Cicchetti, p. 3).

Gross Motor Skills: How the individual uses arms and legs for movement and coordination (Sparrow, Balla, \& Cicchetti, p. 3).

Nonvocal: Refers to individuals with no intelligible speech (Johnson-Martin, Wolters, \& Stowers, p. 24).

Receptive Communication: What the individual understands (Sparrow, Balla, \& Cicchetti, p. 3).

Receptive Language: The ability to understand what we hear or read (Boone, p.32).

Severe Cerebral Palsy: Extreme motor dysfunction on all gross and fine motor channels, such that the individuals are quadriplegic, mobile only by wheel chair, unable to perform self-care activities or to use their hands to manipulate objects, and anarthric or severely dysarthric (Berninger \& Gans, p. 45). 
CHAPTER II

\title{
REVIEW OF THE LITERATURE
}

\section{DEFINITION, CLASSIFICATION, TOPOGRAPHY AND SEVERITY OF CEREBRAL PALSY}

\begin{abstract}
Cerebral palsy was defined by McDonald (1987) as a multiply handicapping condition caused by brain abnormality resulting from maldevelopment or damage occurring before, during, or shortly after birth and characterized by motor dysfunction and a variety of associated problems (p. 3). Associated problems such as impairments in cognitive functioning and communication, and difficulties with socialemotional development, academic success, and seizure disorders may be more limiting than the underlying motor dysfunction itself (McDonald, 1987).

\section{Classification}

Cerebral palsy is a general term used to describe a diverse population with motor impairments. There are many different symptoms of the underlying motor disorder, hence, several nosological systems are in use to classify individuals within this population. The following subgroups described in this thesis are those suggested by the American Academy of Cerebral Palsy 
(AACP) (McDonald, 1987). O' Reilly and Walentynowicz (1981) offer a percentage for each category based on their St. Louis study of 2,004 cases obtained from a metropolitan cerebral palsy clinic.

Spasticity. This is the most common type of cerebral palsy, where a hyperactive stretch reflex is the distinguishing feature. In the normal population, a stretch reflex is imperative for the maintenance of posture and muscle tone. In this subgroup, however, exaggerated stretch reflexes result in impaired mobility, abnormal postures and contractures (McDonald, 1987). In the 1981 St. Louis study, $62.8 \%$ of the clients seen for treatment in the clinic were diagnosed as having spastic cerebral palsy.

Athetosis. Uncontrollable and arrhythmic movement is the identifying feature of athetosis. This is the second most common type of cerebral palsy, where $11.7 \%$ of the subjects in St. Louis study fell into this category. The involuntary movement observed in this subgroup makes it almost impossible to perform simple motor acts (McDonald, 1987).

Rigidity. "The distinguishing neuromuscular characteristic of rigidity is resistance to flexion and extension 
movements resulting from continuous, simultaneous contraction of both the agonist and antagonist muscle groups" (McDonald, 1987). Individuals with this type of cerebral palsy are capable of a limited range of slow movement. In the St. Louis survey, $7.2 \%$ of the subjects were diagnosed as having rigid cerebral palsy.

Ataxia. This form of cerebral palsy is most commonly diagnosed after the child begins to walk because it is characterized by incoordination and difficulty in the maintenance of balance. Hypotonia or muscular weakness may accompany this disorder (McDonald, 1987). In the St. Louis study, $4.9 \%$ of the subjects were diagnosed as having ataxic cerebral palsy.

Tremor. In this subgroup, repetitive, rhythmic involuntary contractions of the flexor and extensor muscles are observed. These tremors can be intentional, appearing with voluntary movement, or nonintentional, present during rest and continue with intentional movement (McDonald, 1987). Of the entire sample of 2,004 subjects in the St. Louis study, only $0.3 \%$ were diagnosed with tremor cerebral palsy.

Atonia. Atonia, specifically defined, means without or 
deficient in muscle tone (McDonald, 1987). In the St. Louis survey, $1.1 \%$ of the sample were diagnosed as having cerebral palsy of the atonic type.

Mixed. Individuals with cerebral palsy are unique, hence, some exhibit combinations of neuromuscular impairment. Schleichkorn (1983) found that the most common combination is spasticity in the lower extremities and athetosis in the hands and arms (McDonald, 1987). In the study based in St. Louis, 12\% of the sample cases were diagnosed as having mixed cerebral palsy.

\section{Topography}

Individuals with cerebral palsy are further classified into subgroups based on the topography, or number and location of limbs affected by the motor impairment. The four most common topographies are listed and described below (McDonald, 1987):

Hemiplegia: One entire side of the body is affected.

Paraplegia: Only the legs are involved.

Quadraplegia: All four limbs are involved.

Diplegia:
All four extremities affected, with the legs primarily and the arms only slightly involved. 
Severity

The American Academy for Cerebral Palsy has provided guidelines for the definition of the degree of severity of motor impairment in terms of functional capacity (Minear, 1956).

Class I- No practical limitation of activity

Class II- Slight to moderate limitation of activity

Class III- Moderate to great limitation of activity

Class IV- Unable to carry on any useful physical activity.

In 1977 , Rusk proposed a more descriptive and widely used set of guidelines to determine the severity of motor disorder. He based the following criteria on the individuals competence in carrying out activities of daily living.

Mild: A person with self-help skills adequate for caring for daily personal needs, who ambulates without appliances and has no speech problem.

Moderate: Self-help skills are inadequate, and the person may need special equipment for ambulation. Speech may be defective. 
Severe: Even with treatment and the use of adaptive equipment, the prognosis for developing self-help skills, ambulation, and functional speech is poor. (McDonald, p. 7)

\section{PERCEPTUAL - MOTOR, COGNITIVE, AND COMMUNICATION IMPAIRMENTS IN CEREBRAL PALSY}

Many obstacles exist in the developmental path of children with cerebral palsy. Motor problems exhibited by this population can affect perceptual and cognitive skills. These, in turn, may hinder the development of speech and language (Carlson, 1987).

\section{Perceptual - Motor Effects}

Children without motor limitations will explore their environment through the use of speech and physical interaction across a variety of objects, contexts, and communication partners. Nondisabled children will receive and process feedback from these interactions, hence, the development of cognitive and language foundational skills (McNaughton, 1993). 
Children with cerebral palsy are often affected by perceptual problems ( i.e. visual and auditory acuity deficits and tactile motokinesthetic feedback disruptions) which may distort and limit the environmental information received by the child. Infants with cerebral palsy are at risk for sensorineural and conductive hearing loss, as well as, oculomotor defects and central processing problems. Body sensations may be affected in children with cerebral palsy where some may have diminished sensitivity while others are tactile defensive. Additionally, proprioception, kinesthesis and vestibular motion relating to the child's posture and movement may be diminished or disordered. These difficulties further reduce the quantity and quality of childhood experiences from which language is based (Carlson, 1987).

Speech production is adversely affected in this population. The act of speaking requires precise coordination of the muscles which control respiratory, phonatory, and articulatory movements. Again, the effect of the motor impairment manifests itself differently from individual to individual and may change over time (Carlson, 1987). 


\section{Cognitive Effects}

Motor and perceptual problems found in this population can detrimentally affect the valid assessment of cognition. The motorically impaired child may interact with objects in the environment in a sensorimotor fashion due to lack of exposure, thus leading an observer to underrate the child's cognitive skills. Children with age appropriate cognitive skills have been misdiagnosed as being cognitively impaired solely because accommodations for their motor limitations were not made during assessment (Carlson, 1987).

The development of symbolic representational skills may be delayed in children with cerebral palsy due to the limited quantity and quality of controlled motor behavior available to this population (McNaughton, 1993). Initiation of interactions with objects and others in the environment provide the nonimpaired child with a variety of experiences from which a symbolic knowledge base may be built. Conversely, children with motor impairments must learn from observing the behavior of others in his/her environment, not necessarily directly interacting with the objects or people within it (McNaughton, 1993). "This behavior may or may not result in 
feedback that is at the appropriate developmental level and hence interpretable by the child" (McNaughton, 1993).

Likewise, the use of expressive language in the population with motor impairments is delayed which, in effect, creates a lack of experience with the use of a symbolic mode for communication purposes (McNaughton, 1993). McNaughton asserts that these children "must be able to control some form of aided system (a communication board or a voice output device containing a graphic representational system) before they can initiate their intentions in a language medium." Language usage by the child's communication partners which directly correspond to his/her developmental level can only enhance, not hinder, the development of symbolic representational skills (McNaughton, 1993).

It is generally believed that there is a much greater incidence of mental retardation in the population with cerebral palsy than in the nonimpaired population. The incidence and degree of retardation is related to the type and extent of motor impairment. However, since there are documented accounts of people with cerebral palsy with age appropriate cognitive skills, and because of obvious limitations in cognitive testing materials, 
one must be skeptical of the previously reported estimates of mental retardation in this population (Johnson-Martin, Wolters, \& Stowers, 1987).

\section{Communication Effects}

The atypical movement patterns observed in cerebral palsy can impinge on the child's exploration and interaction with the environment with its impact varying based on the physiological site affected and the degree of involvement (Carlson, 1987). These preliminary movements are the basis for infant communication which establish a foundation for later speech and language development (Piaget, 1952; Piaget \& Inhelder, 1969).

Language development is affected by the motor impairment in two ways: (a) exposure to consistent motor experiences which aid in the perception of basic concepts later used in language are unavailable to children with cerebral palsy, and (b) the quantity and quality of successful communicative interactions through which the child discovers the function of language is lacking (Carlson, 1987).

Children with motor impairments lack in the experience of basic cause and effect relationships relating to environmental 
changes due to vocalizing and volitional movement which comprise early speech attempts (Carlson, 1987). Early language development may be negatively affected in this population because of minimal experience in the following areas: "the social use of talk to share meanings with others; the demonstrated knowledge of speech structures by applying the rules of ordering words and making agreements between words; the different purposes of talk, involving the child's meanings, his or her thinking, and the kind of information he or she is using language to convey; and metalinguistic awareness" (McNaughton, p. 61). Mildly impaired children with cerebral palsy may not be deficient in these experiences, however, their active participation in communication may be delayed and/or asynchronous with their cognitive skills (Carlson, 1987).

Kraat (1991) inquired whether different experiences and communicative environments could result in an unique pattern of language acquisition for children with cerebral palsy. As a result of their physical limitations, these children may not have been exposed to nor interacted with the environment in a similar manner compared to their non-disabled peers (Kraat, 1991). Lack of experience with cause/effect relationships and 
the manipulation of objects impacts the development of skills required for learning and perceptual refinement in adverse ways (Parker, 1987).

In a three-part study conducted by Light, Collier, and Parnes (1985), the communicative interaction patterns of eight children and their caregivers were observed and analyzed in terms of discourse patterns, communicative functions, and modes of communication during a twenty minute free play session. Each child was between the ages of four and six, nonspeaking and physically disabled since birth. These examiners found a highly asymmetrical pattern of discourse between the children and their caregivers. Caregivers were observed to control the communicative interaction through "occupying more of the conversational space, by initiating topics, and by exerting maximal summoning power in their turns and demanding specific responses from the children" (Light, Collier, and Parnes, 1985a).

Next, communicative functions were analyzed during the previous free-play sample with the caregiver and compared to structured play situations with a clinician trained in augmentative communication strategies. It was discovered that 
during free play with the caregiver, the children produced a majority of yes/no responses (39\%) or direct responses to information requested by the caregiver (18.4\%). It was further noted that the children in the study rarely requested information or clarification, nor produced social greetings and closings. A broader range of communicative functions were elicited by the clinician through the use of sabotage techniques (Light, Collier, and Parnes, 1985b).

Finally, the modes of communication were assessed relative to this sample and their primary caregivers. It was found that multiple modes were used by this population of augmentative users to communicate; not limited to the use of the augmentative device. The children were observed to use vocalization, gesture, and/or eye gaze, either alone or in combination, during $81.8 \%$ of their communicative turns (confirmations and denials). Interestingly, only $18.2 \%$ of the children's communicative turns, primarily provisions of information and clarification, were expressed through the use of augmentative devices (Light, Collier, and Parnes, 1985c).

Holistically, the motor impairments observed in children with cerebral palsy can adversely affect social communicative 
interactions. Facial expressions, visual tracking, and fixation are important components in the communicative partners' deciphering of the child's intent through body language. If a child's communicative attempts go unrecognized, they may never understand the concept of initiation of control over their environment and the people within it. In fact, in the more severely impaired child, motoric responses to the environment may be distorted, delayed, absent, or even dependent upon specific cues supplied by familiar communicative partners (Carlson, 1987).

Receptive Language Research in Cerebral Palsy

Bishop, Brown, and Robson (1990) inquired as to how a child's motor limitation may affect his/her ability to understand and use language, or verbal processes, in mental operations. A sample of twenty-four subjects with impaired speech production were compared to a control group with normal speech production on receptive language measures. All of the subjects were diagnosed with cerebral palsy with the groups matched according to age and nonverbal ability. Results indicated that the speech-impaired group were less successful compared to the control group in terms of receptive vocabulary scores, but not in 
the comprehension of grammatical forms (Bishop, Brown, and Robson, 1990).

In summary, group studies of the receptive language development in children with cerebral palsy are extremely limited. The Bishop et. al. study found receptive vocabulary scores to be affected by motor impairments, whereas, comprehension of grammatical forms are not. It is very difficult to provide appropriate intervention programs for these children when obvious motor limitations mask their underlying cognitive and receptive language capacities. These children have the right to an appropriate education, therefore it is our obligation, as professionals in the field of speech and language pathology, to provide a valid yet comprehensive assessment independent of existing motor limitations.

DIFFICULTIES IN THE ASSESSMENT OF INDIVIDUALS WITH CEREBRAL PALSY AND POTENTIAL SOLUTIONS

Unique problems are posed when assessing children with cerebral palsy because of their motor limitations and atypical behaviors. Standardized tests do not allow for flexibility in the interpretation of communicative behaviors in this population. Information from adaptive testing, skilled observation, and 
parent interviews can complement that which is derived from standardized testing (Carlson, 1987).

Norm-referenced tests are commonly used when qualifying children for special services. Unfortunately, these measures depend heavily upon motor skills and may not provide an accurate assessment of receptive nor expressive communication skills in children with cerebral palsy. Criterionreferenced tests are more flexible in that materials and procedures may be substituted for relevant items previously experienced by the child. Thus, a more accurate interpretation of the child's communicative abilities emerge when using a criterion-referenced measure (Carlson, 1987).

\section{Adaptation}

Adaptation of measures used during the assessment of children with cerebral palsy is essential for valid results regarding levels of functioning. In the adaptation, the intent or purpose of the instrument or items within it remain undisturbed, yet the materials and mode of indication or response may be changed to suit each individual's motor abilities (Carlson, 1987). For example, item \#15 in the Communication Domain of The Vineland Adaptive Behavior 
Scales: Interview Edition, Survey Form, (Sparrow, Balla, \& Cicchetti,1984), focuses on the verbal production of two word phrases. This item may be adapted for children with cerebral palsy to allow credit for the gestural production of two word combinations, so that their communication skills are not discounted based on the underlying motor impairment of the speech mechanism.

\section{Parent Report}

Parent interviews and checklists are invaluable resources for professionals compiling communicative information. In addition to being cost-and-time effective, they can provide a more representative sample of what the child is capable of doing in more than just one setting or one situation (Fenson, et. al., 1994). Assessment in the form of a language sample or an observation within the clinic restricts the amount of information available to the professional in making a valid diagnosis or an appropriate intervention plan. Parents of children with cerebral palsy are more capable in recognizing intentional communication and may provide the familiar contextual cues needed to stimulate its' production (Carlson, 1987).

In a longitudinal study conducted by Bates et. al. (1988) 
the relationship between parent report of vocabulary and scores obtained through the collection of a language sample in typically developing children was examined. The parent report of vocabulary skills was correlated with the vocabulary collected through the language sample at $r=+0.83$, thus indicating the validity of obtaining information through parent report versus collecting and analyzing an entire language sample.

Soriano, Paul, and Cohen (1988) examined the correlation between Vineland communication domain scores obtained through parent interview and scores obtained from direct standardized testing in their longitudinal study of children with developmental language disorders. These researchers found a high correlation between parent report and other direct measures of receptive and expressive language (.93 and .84 respectively).

\section{Observation}

Observation, an informal assessment technique, is another method used when assessing children with cerebral palsy. The examiner is able to discover how the child uses movement, eye gaze, and vocalizations in relation to objects, people, and routines in his/her environment (Carlson, 1987). Unfortunately, the 
potentially long delays in the response time of children with motor impairments could negatively effect the amount of information obtained within one clinical session. Therefore, due to the time constraints found within the clinical setting, a combination of observation and parent report may be the most reasonable method of assessment.

In summary, there are many avenues that professionals can take in regards to the assessment of the child with cerebral palsy: adaptation of norm-referenced tests, criterion-referenced tests, parent interview or checklist, or observation. It is important that professionals remain flexible in the instruments, materials, and method of indication used during the assessment process, due to the uniqueness of each individual with cerebral palsy. It would be an injustice to the child if his/her abilities were not discovered because of invalid assessment instruments and/or the compounding effect of motor dysfunction.

There is a great need for efficient, yet reliable methods in the assessment of children with cerebral palsy particularly in the area of receptive language. It is the intention of this study to provide data that will indicate parent report as a valid means of measuring receptive language in this population. This finding 
could potentially save professionals considerable time previously spent adapting materials and administering direct assessments which are not normed for use with the population with motor impairments. This examiner will attempt to provide data that further supports previous research which documented the importance of not assuming a child's receptive language understanding based on his/her expressive language skills. 
CHAPTER III

\section{METHODS AND PROCEDURES}

\section{METHODS}

\section{Subjects:}

This study included 15 children, 10 males and 5 females, who were participating in a larger study at Portland State University. These children were between the ages of 3-years and 6-years at the time of participation and were all currently receiving special services through local early intervention programs.

Each child was previously diagnosed with cerebral palsy, although types of impairment differed from individual to individual. This examiner classified each subject into mild, moderate, and severe groups based on severity of motor disorder using the criteria proposed by Rusk (1977). In this study there were two mildly impaired (13.3\%), seven moderately impaired (46.7\%), and six severely impaired subjects (40.0\%) (See Table 1). Of the total sample, subjects five and six, were born from a fraternal triplet pregnancy where one sibling was left unaffected. Additionally, subject number thirteen was a fraternal twin with his sister born unimpaired. 
TABLE 1

SUMMARY OF SUBJECTS

\begin{tabular}{llll} 
SUBJECT \# & AGE IN MONTHS & GENDER & GROUP \\
\hline 3 & 68 & male & mild \\
9 & 68 & female & mild \\
\hline 6 & 37 & male & moderate \\
4 & 62 & male & moderate \\
12 & 62 & male & moderate \\
7 & 52 & male & moderate \\
11 & 47 & female & moderate \\
2 & 56 & female & moderate \\
13 & 41 & female & moderate \\
\hline 8 & & & \\
1 & 72 & male & severe \\
10 & 44 & male & severe \\
14 & 50 & male & severe \\
15 & 71 & male & severe \\
5 & 43 & male & severe \\
& 37 & female & severe \\
\hline
\end{tabular}

The subjects were obtained from a variety of sources (local hospitals, early intervention programs, and word of mouth) as a part of a previous study conducted at Portland State University in the Speech and Hearing Sciences Program. The following eligibility criteria were used in the selection of the participants:

1. Age between three and six years. 
2. A diagnosis of cerebral palsy by a medical professional.

3. Moderate to severe motor speech impairments that preclude the use of speech as a primary mode of communication.

4. Adequate motor skills to participate in the study using hand pointing or eye gaze as the method of indication.

5. English as a primary language in the home.

6. No uncorrected hearing or vision impairments.

7. No diagnosis of autism, Down Syndrome, or other genetic or metabolic disorder that could interfere with cognitive development.

8. An adult in the home who can complete questionnaires used in the study.

The nature of the study was explained both orally and in writing to the parents. Each parent signed a written permission form for participation in the study.

\section{Instruments}

The Vineland Adaptive Behavior Scales: Interview Edition, Survey Form, measures adaptive behavior in four domains: 
Communication, Daily Living Skills, Socialization, and Motor Skills (Sparrow, Balla, \& Cicchetti, 1984). The survey form, containing 297 items, is administered in a semi-structured interview format with the parent or caregiver and lasts between 20 and 60 minutes. Norm-referenced information such as raw scores, standard scores, age equivalents, percentile ranks, stanines and adaptive levels were obtained based on the performance of representative national standardized samples of approximately 4,800 handicapped and nonhandicapped individuals from birth to 18-years, 11-months old. Each domain is comprised of several subdomains. The following is a description of content for each subdomain (p. 3):

\section{Communication -}

Receptive:

Expressive:

Written:

What the individual understands

What the individual says

What the individual reads or writes

Daily Living Skills-

Personal: How the individual eats, dresses, and practices personal hygiene

Domestic: What household tasks the individual performs

Community: How the individual uses time, money, the telephone, and job

Socialization skills

Interpersonal

Relationships: How the individual interacts with 
Play and

others

Leisure Time: How the individual plays and uses leisure time

Coping Skills: How the individual demonstrates responsibility and sensitivity to others

\section{Motor Skills-}

Gross: How the individual uses arms and legs for movement and coordination

Fine: How the individual uses hands and fingers to manipulate objects

\section{Adaptive Behavior} Composite:

A composite of the Communication, Daily Living Skills, Socialization, and Motor Skills domains

The Vineland (VABS) has been validated against the The Peabody Picture Vocabulary Test - Revised (PPVT-R; Dunn \& Dunn, 1981). The PPVT-R was administered to the original Vineland national standardization sample of 2,018 individuals between the ages of 2-6-0 through 18-11-30. Analysis of the relationship between the VABS and PPVT-R standard scores yielded a low but positive correlation. The scores obtained in the Communication domain yielded the strongest correlation to 
the PPVT-R because of the language content common to both measures.

The Peabody Picture Vocabulary Test-Revised, Form L, (PPVT-R), was developed by Dunn and Dunn in 1981 as a standardized measure to assess a subject's receptive vocabulary for Standard American English. This instrument was normed for individuals aged 2-years, 6-months through 40-years. Raw scores are converted to age equivalents, percentile rankings, standard scores, and stanines. For the purposes of this study, the receptive vocabulary standard score and/or age equivalent were reported.

Subjects were asked to indicate one picture out of a set of four which most closely corresponds with the target word provided by the examiner. Modifications were made in order to allow for a larger target for gross motor pointing with the arm or clenched fist, as well as, to aid in the use of eye gaze as a method of indication (See Appendix E). Eye gaze was used as the method of indication in $20 \%(3 / 15)$ of the direct assessment sessions. In one case, a male subject using eye gaze, was unable to indicate a choice in a set of four pictures as indicated by unreliable results obtained during the pretest procedures described in the 
following section. However, the subject was able to indicate reliably when the field was limited to two choices as demonstrated by his ability to select the target items on five consecutive trials.

\section{PROCEDURES}

A physical therapy student from Oregon Health Sciences University (OHSU) accompanied the examiner to each session. Positioning concerns were evaluated and the most appropriate positioning was ascertained in order to reduce abnormal tone and reflexes so that each subject could utilize his/her residual movement abilities during the direct assessment.

Each subject in the study participated in a two and a half hour in-home assessment session. Initially, this examiner provided each parent with a consent form which contained details regarding continued participation in the larger study at Portland State University. Each parent was asked to sign the form, thus indicating their continued interest in their participation in the longitudinal study. Across all subjects, the mothers participated as the informants for this study.

Next, each informant was asked to share information regarding their child's development in a structured interview 
with the examiner (VABS). This examiner asked open-ended questions, per Vineland protocol, regarding the subject's adaptive behavior skills in the domains of Communication, Daily Living, Socialization, and Fine and Gross Motor, respectively. For example, in order to obtain the answer for question \#19 in the Daily Living Skills Domain, (Asks to use toilet) this examiner asked the parent, "Tell me about your child's toileting skills." The parent would then provide this examiner with a summary of the child's toileting skills. If the answer to the question could inferred by the parents response (i.e. "She's not potty trained yet and wears diapers all the time") this examiner would score the item and move on. If the answer could not be inferred, this examiner would ask a leading question (i.e. "How do you know when your child needs to use the restroom?") and continue to specify until the answer was satisfactorily obtained.

Modifications to the target questions used in the Vineland Interview format in the Communication and Socialization Domains were made in order to address the motor limitations in this population (See Table 2). Modifications were unnecessary for the target questions found in the Daily Living and Motor Skills domains, hence these sections were administered per 
protocol. This examiner obtained a basal level of seven consecutive items scored "2 " (Yes, usually) and progressed through the interview until a ceiling of seven consecutive items scored "0" (No, never) was reached. 
TABLE 2

MODIFICATIONS TO VINELAND QUESTIONS

\begin{tabular}{|c|c|}
\hline Actual Questions & Modifications \\
\hline \multicolumn{2}{|l|}{ Communication Domain } \\
\hline $\begin{array}{l}\text { 1. Turns eyes and head toward } \\
\text { sound. }\end{array}$ & $\begin{array}{l}\text { How can you tell when your child } \\
\text { listens? }\end{array}$ \\
\hline $\begin{array}{l}\text { 5. Raises arms when caregiver } \\
\text { says, "Come here" or "Up." }\end{array}$ & $\begin{array}{l}\text { What does your child do when you } \\
\text { call his/her name or when you want } \\
\text { to pick your child up? }\end{array}$ \\
\hline $\begin{array}{l}\text { 8. Demonstrates understanding of } \\
\text { the meaning of at least } 10 \text { words. }\end{array}$ & $\begin{array}{l}\text { Does your child gesture } \\
\text { appropriately for } 10 \text { items? For } \\
\text { example, when dressing will he/she } \\
\text { move or look at the body part } \\
\text { requested? }\end{array}$ \\
\hline $\begin{array}{l}\text { 14. Uses first names or nicknames } \\
\text { of siblings, friends, or peers, or } \\
\text { states their names when asked. }\end{array}$ & $\begin{array}{l}\text { Does your child differentiate } \\
\text { vocalizations when labeling } \\
\text { significant people or animals in } \\
\text { his/her environment? }\end{array}$ \\
\hline $\begin{array}{l}\text { 15. Uses phrases containing a } \\
\text { noun and a verb, or two nouns. }\end{array}$ & $\begin{array}{l}\text { Does your child use any two word } \\
\text { or two gesture combinations? }\end{array}$ \\
\hline $\begin{array}{l}\text { 20. Spontaneously relates } \\
\text { experiences in simple terms. }\end{array}$ & $\begin{array}{l}\text { How does your child tell you what } \\
\text { happened at school or in the past? }\end{array}$ \\
\hline \multicolumn{2}{|l|}{ Socialization Domain } \\
\hline $\begin{array}{l}\text { 14. Imitates simple adult } \\
\text { movements, such as clapping } \\
\text { hands or waving good-bye, in } \\
\text { response to a model. }\end{array}$ & $\begin{array}{l}\text { Does your child imitate motorically } \\
\text { appropriate actions in response to a } \\
\text { model? For example, blinking eyes } \\
\text { or swinging feet?. }\end{array}$ \\
\hline $\begin{array}{l}\text { 23. Says "please" when asking for } \\
\text { something. }\end{array}$ & $\begin{array}{l}\text { Does your child gesture for "please" } \\
\text { when asking for something? }\end{array}$ \\
\hline $\begin{array}{l}\text { 24. Labels happiness, sadness, } \\
\text { fear, and anger in self. }\end{array}$ & $\begin{array}{l}\text { Does your child use gestures or } \\
\text { sign language to label happiness, } \\
\text { sadness, fear and anger in his/her } \\
\text { self? }\end{array}$ \\
\hline
\end{tabular}


Lastly, this examiner introduced the Peabody Picture

Vocabulary Test- Revised format to each subject. Four instant Polaroid photos of familiar people or objects in the home were taken and used to assess method, latency, and reliability of each subject's response before the modified format PPVT-R was administered. This examiner asked each informant (mother) to designate four items in the home that each child would clearly know the label or name. Most often, Polaroid photos of siblings, family pets, or the subject's adaptive equipment (i.e. wheelchair or walker) were used.

Next, the four pictures of familiar objects were displayed in rows and column of two by two on an appropriate surface (i.e. table, floor, lap tray, or clipboard) corresponding to the optimal positioning of each subject whether sitting in a wheelchair, at a table, or on the floor. Each subject was then asked to point to the one picture from the set of four, either through hand pointing or eye gaze, that most accurately depicted the stimulus word provided. The photos were rearranged in a different format after each trial. Each response was positively reinforced either by verbal praise, touch, clapping, or a thumbs-up sign, in order to enhance the maintenance of attention and motivation to 
the task. The direct administration of the PPVT-R was initiated once the child demonstrated reliable responses using the Polaroid photos on five out of five trials.

The example stimuli provided in the PPVT-R series of plates were administered in order to train the subjects to the task using the modified size format. Once reliable responses were obtained for the example stimuli the direct assessment was initiated. This examiner administered the assessment, per Peabody protocol, until a basal of the highest eight consecutive correct responses and a ceiling of the lowest eight consecutive responses containing six errors was obtained for all subjects.

\section{RELIABILITY}

A certified Speech and Language Pathologist with experience in administering both the VABS and PPVT-R accompanied this examiner to $13 \%$ of the sessions used in this study. The trained examiner scored along with this examiner during the in-home sessions. The inter-rater reliability was found to be $100 \%$ for the VABS administration and $97.5 \%$ for the PPVT-R. This reliability rating included one subject who used eye gaze and another who used finger pointing as their method of indication during the direct assessment. 
Each subject was assigned a severity level based on existing motor impairment using the descriptive guidelines proposed by Rusk (1977). Another examiner, familiar with each subject and Rusk's guidelines, grouped each subject into the categories of mild, moderate, and severe. Both examiners agreed on the category for 13 out of 15 subjects which yielded an interrater reliability score of $87 \%$.

\section{STATISTICAL ANALYSIS}

The Spearman correlation coefficient (Woods, et. al., 1986) was used to determine the relationship between variables for questions one, two, and three. The Spearman correlation coefficient can solely be used "as a test statistic for testing the hypothesis that two variables are independent of one another [and was] designed to cope with data sets which are not normally distributed" (Woods et. al., p. 173). The first question attempted to examine parent report versus direct assessment as a reliable and valid clinical tool. Questions two and three attempted to examine the relationship between motor skills and receptive communication skills as measured by the VABS and PPVT-R. Significance of the relationship was established by an alpha value of .05 using the SYSTAT program. 
Two separate one-way analyses of variance (ANOVA) (Woods, et. al. 1986) were performed to determine explicit differences between variables, receptive language and vocabulary skills, among the different severity levels of motor impairment (See Table 3). An ANOVA format for analysis is typically used to compare several means simultaneously "according to a single (hence 'one-way') criterion variable" (Woods, et. al., p. 197).

\section{TABLE 3}

ANOVA MODELS TO BE USED IN ANALYSIS

Severity VABS- Receptive Language Quotient

\section{Mild}

Moderate

Severe

Severity PPVT-R- Receptive Vocabulary Quotient

\section{Mild}

Moderate

Severe 
CHAPTER IV

\section{RESULTS AND DISCUSSION}

\section{RESULTS}

Results of the present study were analyzed through the use of Spearman correlation coefficients and two one-way measures of analysis of variance (ANOVA).

Review of the Research Questions

1) Does a significant relationship exist between the receptive communication age equivalent obtained through parent interview (VABS) and the receptive vocabulary age equivalent obtained through direct assessment (PPVT-R)?

2) Does a significant relationship exist between the motor skills age equivalent and the receptive communication age equivalent, both obtained through parent interview (VABS)?

3) Does a significant relationship exist between the motor skills standard score obtained through parent interview (VABS) and the receptive vocabulary standard score obtained through direct assessment (PPVT-R)? 
4) Do significant differences exist among the different diagnostic categories of motor impairment in terms of the receptive communication developmental quotient (VABS) and the receptive vocabulary standard score (PPVT-R)?

\section{Descriptive Results}

The results of this study are displayed in two tables in order to separate the data from the assessments which provide standard scores from those which provide age equivalents.

Table 4 contains the means, standard deviations, and ranges for each group (mild, moderate, and severe) and for the PPVT-R receptive vocabulary standard scores and VABS motor skills standard scores.

Table 5 contains the means, standard deviations, and ranges for each group (mild, moderate, and severe) and for the PPVT-R receptive vocabulary age equivalent, VABS receptive communication age equivalent, and VABS motor skills age equivalent. 
TABLE 4

GROUP DESCRIPTIVE STATISTICS AND STANDARD SCORES

\begin{tabular}{llll|}
\hline Group & $\begin{array}{l}\text { Age (mo.) } \\
\text { mean } \\
\text { (s. d.) } \\
\text { [range] }\end{array}$ & $\begin{array}{l}\text { PPVT-R (SS) } \\
\text { mean } \\
\text { (s. d.) } \\
\text { [range] }\end{array}$ & $\begin{array}{l}\text { VABS Motor (SS) } \\
\text { mean } \\
\text { (s. d.) } \\
\text { [range] }\end{array}$ \\
\hline Mild & 68 & 83 & 92.5 \\
$\mathrm{n}=2$ & $(0)$ & $(1.41)$ & $(31.82)$ \\
& {$[68-68]$} & {$[82-84]$} & {$[70-115]$} \\
\hline $\begin{array}{l}\text { Moderate } \\
\mathrm{n}=7\end{array}$ & 51 & 74.43 & 48.29 \\
& $(9.83)$ & $(24.3)$ & $(9.91)$ \\
\hdashline & {$[37-62]$} & {$[39-108]$} & {$[38-67]$} \\
\hline Severe & 52.83 & 60.33 & 31.67 \\
$\mathrm{n}=6$ & $(15.04)$ & $(17.95)$ & $(14.49)$ \\
& {$[37-72]$} & {$[39-79]$} & {$[19-58]$} \\
\hline
\end{tabular}


TABLE 5

GROUP DESCRIPTIVE STATISTICS AND AGE EQUIVALENTS

\begin{tabular}{|c|c|c|c|}
\hline Group & $\begin{array}{l}\text { PPVT-R (AE) } \\
\text { mean } \\
\text { (s. d.) } \\
\text { [range] }\end{array}$ & $\begin{array}{l}\text { VABS * (AE) } \\
\text { Receptive } \\
\text { mean } \\
\text { (s. d.) } \\
\text { [range] }\end{array}$ & $\begin{array}{l}\text { VABS Motor } \\
\text { (AE) } \\
\text { mean } \\
\text { (s. d.) } \\
\text { [range] }\end{array}$ \\
\hline $\begin{array}{l}\text { Mild } \\
n=2\end{array}$ & $\begin{array}{l}52 \\
(2.83) \\
{[50-54]}\end{array}$ & {$\left[\begin{array}{ll}47 & \\
(0) & \\
{\left[\begin{array}{ll}47 & -47]\end{array}\right]}\end{array}\right.$} & $\begin{array}{l}50.5 \\
(6.36) \\
{[46-55]}\end{array}$ \\
\hline $\begin{array}{l}\text { Moderate } \\
n=7\end{array}$ & $\begin{array}{l}36.14 \\
(8.71) \\
{[27-50]}\end{array}$ & $\begin{array}{l}37.43 \\
(12.45) \\
{[18-47]}\end{array}$ & $\begin{array}{l}19.57 \\
(4.31) \\
{[14-28]}\end{array}$ \\
\hline $\begin{array}{l}\text { Severe } \\
n=6\end{array}$ & $\begin{array}{l}31.17 \\
(9.41) \\
{[23-49]}\end{array}$ & $\mid \begin{array}{l}22.5 \\
(3.99) \\
{[18-30]}\end{array}$ & $\begin{array}{l}9.17 \\
(9.45) \\
{[3-28]}\end{array}$ \\
\hline
\end{tabular}

* No Standard Score Provided

$\underline{\text { Spearman Correlation Results }}$

A Spearman correlation coefficient was performed in order to examine the the strength of the relationship between the measures described in research questions one, two and three.

In regards to question one, parent report (VABS receptive communication age equivalent) vs. direct assessment (PPVT-R receptive vocabulary age equivalent) of receptive communication skills, the statistical analysis determined a 
positive relationship among the two methods of assessment. A correlation coefficient of 0.6497 and p-value of 0.009 was obtained, thus the null hypothesis was rejected.

Statistical analysis of question two, receptive communication age equivalent (VABS) vs. motor skills age equivalent (VABS), resulted in a correlation coefficient of 0.3982 and $p$-value of 0.142 . No significant relationship between the variables was obtained so the null hypothesis was not rejected.

The relationship between the receptive vocabulary standard score (PPVT-R) and motor skills standard score (VABS) in question three was not found to be statistically significant. A correlation coefficient of 0.4668 and p-value of 0.079 was obtained, therefore the null hypothesis was not rejected. Two one-way measures of analysis (ANOVA) were performed in order to examine whether or not a significant difference existed, among the categories of motor impairment in terms of receptive communication (VABS) and receptive vocabulary scores (PPVT-R). There were three levels of severity: mild, moderate, and severe. One ANOVA examined the effect of this variable on the dependent variable receptive vocabulary standard score (PPVT-R). The second one-way 
ANOVA examined the effect of severity level on receptive communication developmental quotient (VABS). A standard score was not available for the Receptive Communication section of the VABS, however an age equivalent was reported. This examiner derived the developmental quotient used in the analysis for question number four from a ratio consisting of the VABS age equivalent divided by the real age of the subject (i.e. age equivalent $(25) /$ real age $(40)=.62 \times 100=$ developmental quotient of 62).

A post-hoc $\underline{\mathrm{F}}$ - test indicated no statistically significant difference among the three severity groups (mild, moderate, severe) in terms of receptive vocabulary standard scores (PPVTR) $(\mathrm{F}$ Prob. $=.3334)$. Similar results were obtained when a posthoc $\underline{F}$ - test was run on the dependent variable of the receptive communication developmental quotient (VABS). No statistically significant differences existed between the groups $(\mathrm{F}$ Prob. $=$ .1234). The null hypothesis was not rejected for question four, indicating there were no significant differences among the groups based on motor impairment in terms of receptive communication or receptive vocabulary scores. 


\section{DISCUSSION}

The results of this study indicate that parent report/interview is a reliable means for assessing the receptive communication skills of children with cerebral palsy when compared to direct assessment. Assessment using parent report can save professionals an abundance of time which would have been previously spent adapting test materials and administering test items keeping in mind each child's unique mode of indication and latency of response. Additionally, a parent interview format provides the professional with a vast amount of information in a short period of time from a trained observer (the parent) who knows the child best and can read his/her intentions through any obvious motor difficulties. In fact, a parent interview could be accomplished over the telephone making a clinic visit virtually unnecessary.

This examiner found no significant differences in the receptive communication skills of the preschool-aged children with cerebral palsy based on their levels of severity of motor impairment. Thus, it is to be concluded, in terms of the sample studied, that motor abilities or disabilities do not necessarily reflect underlying receptive language and vocabulary skills. 
Therefore, it is not in the best interest of the child for his/her communicative partners to assume the child's level of understanding language based on obvious motor impairments. 


\section{CHAPTER V}

\section{SUMMARY AND IMPLICATIONS}

\section{SUMMARY}

The purpose of this study was to determine whether or not parent interview/report is a reliable means of assessing receptive communication skills in preschool-aged children with cerebral palsy. Additionally, the relationship between motor skills and receptive language skills were examined. The subject pool was comprised of fifteen children, 10 males and 5 females, between the ages of three to six years who were participating in a longitudinal study at Portland State University. Each subject and his/her mother participated in a two and a half hour inhome assessment session. A physical therapy student accompanied this examiner to the subject's homes in order to address positioning needs before the direct measure was administered. Both the Vineland Adaptive Behavior Scale Interview Format and the Peabody Picture Vocabulary Test Revised were administered to each participating subject.

Results revealed that parent report is a valid means for assessing receptive communication skills in the preschool-aged population with cerebral palsy. However, significant differences 
based on degrees of motor impairment were not found for the development of receptive language skills in this population.

\section{CLINICAL IMPLICATIONS}

The use of a parent report measures such as the VABS was found to yield valid results in the assessment of receptive language skills in children with cerebral palsy when compared to direct assessment. It was found that the parents of children with cerebral palsy are reliable reporters of their child's receptive language skills and did not tend to exaggerate or provide false information to this examiner. This finding further supports the contention that professionals need to either provide a modified direct assessment or a parent report measure in order to obtain a valid representation of skills when assessing children with motor impairments. Additionally, it has been documented by this study that motor skills do not necessarily imply underlying receptive language skills.

Although this study discovered that parents are reliable reporters of receptive communication skills, the Light, Collier, and Parnes (1985) study found that parents of children with cerebral palsy were less responsive to their child's communicative intentions. Parent training in the area of 
responsiveness could enhance the parent-child communicative interaction and assist parents in using what they know about their child's language skills in order to support further communication development.

It is very important to evaluate receptive language in this population before planning intervention since motor dysfunction can potentially mask underlying skills. Speech and language pathologists run the risk of limiting language growth in children with motor impairments when providing augmentative or alternative communication devices without first evaluating current levels of comprehension.

Parent and caregiver training should focus on providing the child with an appropriate language model based on receptive, not expressive, language skills. Speech and language pathologists can assess the receptive communication level of the child and provide parents with suggestions regarding appropriate stimulation activities at that level. Intervention is most effective when the parents are provided with information regarding the philosophies behind the intervention techniques (Carlson, 1987). This information can enable parents to problem solve and develop techniques and strategies that are functional 
within the home setting (Carlson, 1987). An open-forum for communication should be maintained which encourages parents to discuss difficulties, successes, and ongoing needs with the clinician (Carlson, 1987). Speech and language pathologists can work jointly with parents and caregivers to enhance the development of receptive communication skills in the population with motor impairments.

\section{RESEARCH IMPLICATIONS}

Normative data regarding communication development, expressive and receptive, in children with cerebral palsy is not available as yet. The first step towards obtaining this valuable information is to develop valid assessment instruments that are not tainted by primitive reflexes and/or motor dysfunction. Obtaining and assessing a national standardized sample will be a time-consuming process, however, the results of this study indicate the reliability of parent report which, in effect, can expedite the process of data collection.

Although the results of this study did not document specific trends in motor skills and receptive communication development, further research using a larger sample size in each category of severity may uncover significant differences among 
the moderate and severe groups. Trends may exist across the severity levels of motor impairment. Such a trend is suggested by the observation (See Tables $4 \& 5$ ) that scores on the PPVT and $\underline{\text { VABS }}$ receptive subscale are at least one standard deviation higher in the moderate than the severe group. A larger sample might have identified a significant difference between these variables.

This information could not only assist professionals in providing parents with appropriate intervention strategies and techniques, but could also provide parents with a "map of developmental milestones." Thus the parents and caregivers could provide the child with a language model at or slightly above the child's current level of functioning based on the normative information. The provision of appropriate language models will allow the child to constantly move forward in his/her communication development without stagnating at a lower level of functioning. The effect of communication development will enhance the growth of the child, including but not limited to, the areas of cognition and socialization. 


\section{REFERENCES}

Bates, E., Bretherton, I. \& Snyder, L. (1988). From first words to grammar: individual differences and dissociable mechanisms. New York: C.U.P.

Berninger, V. W., \& Gans, B. M. (1986). Language profiles in nonspeaking individuals of normal intelligence with severe cerebral palsy. AAC Augmentative and Alternative Communication, 5 , 45-50.

Bishop, D. V. M., Brown, B. B., \& Robson, J. (1990). The relationship between phoneme discrimination, speech production, and language comprehension in cerebralpalsied in Bloom, F. E., \& Lazerson, A. (1985). Brain, Mind, and Behavior: Second Edition. New York: W. H. Freeman and Company.

Boone, D. R. (1987). Human Communication and Its Disorders. New Jersey: Prentice-Hall, Inc.

Carlson, F. (1987). Communication strategies for infants. In E. McDonald, Treating Cerebral Palsy: For Clinicians by Clinicians. Austin, Texas: PRO-ED, Inc.

Dunn, L.M., \& Dunn, L.M. (1981). Peabody Picture Vocabulary Test- Revised. Circle Pines, MN: American Guidance Service.

Fenson, L., Dale, P. S., Reznick, J. S., Bates, E., Thal, D. J., \& Pethick, S. J. (1994). Variability in early communicative development. Monographs of the Society for Research in Child Development, 59, 1 - 174.

Johnson-Martin, N. M., Wolters, P., \& Stowers, S. (1987). Psychological assessment of the nonvocal, physically handicapped child. Physical and Occupational Therapy in 
Pediatrics, 7, 23-38.

Kraat, A. (1991). Methodological issues in the study of language development for children using AAC systems. In $\mathrm{J}$. Brodin \& E. Bjorck-Akesson (Eds.), Methodological Issues in Research in Augmentative and Alternative Communication: Proceedings from the First ISAAC Research Symposium in Augmentative and Alternative Communication. Stockholm: Swedish Handicap Institute.

Light, J., Collier, B., and Parnes, P. (1985a). Communicative interaction between young nonspeaking physically disabled children and their primary caregivers: Part IDiscourse patterns. AAC Augmentative and Alternative Communication, 1 , p. 74-83.

Light, J., Collier, B., and Parnes, P. (1985b). Communicative interaction between young nonspeaking physically disabled children and their primary caregivers: Part IICommunicative functions. $\mathrm{AAC}$ Augmentative and Alternative Communication, 1, p. 98-107.

Light, J., Collier, B., and Parnes, P. (1985c). Communicative interaction between young nonspeaking physically disabled children and their primary caregivers: Part IIIModes of communication. AAC Augmentative and Alternative Communication. 1, p. 125-133.

McDonald, E. T. (1987). Treating Cerebral Palsy: For Clinicians by Clinicians. Austin, Texas: PRO-ED, Inc.

McNaughton, S. (1993). Graphic representational systems and literacy learning. Topics in Language Disorders, 13, p. 5875.

Minear, W. L. (1956). A classification of cerebral palsy. Pediatrics, 28, 841-852. 
O'Reilly, D. E., \& Walentynowicz, J. E. (1981). Etiological factors in cerebral palsy: An historical review. Developmental Medicine and Child Neurology, 23, 633-642.

Parker, L. G. (1987). Educational Programming. In E. McDonald, Treating Cerebral Palsy: For Clinicians by Clinicians. Austin, Texas: PRO-ED, Inc.

Piaget, J., \& Inhelder, B. (1969). The Psychology of the Child. New York: Basic Books.

Piaget, J. (1952). The Origins of Intelligence in Children. New York: Basic Books.

Rusk, H. (1977). Rehabilitation medicine (4th ed.). St. Louis: C. V. Mosby.

Schleichkorn, J. (1983). Coping with cerebral palsy. Austin, Texas: PRO-ED.

Soriano, D., Paul, R., \& Cohen, D. J. (1988). A report on adaptive behavioral outcomes in adolescents with developmental language disorders. NSSLHA Journal.16, 106-114.

Sparrow, S. S., Balla, D. A., \& Cicchetti, D. V. (1984). Vineland Adaptive Behavior Scales. Circle Pines, MN.: AGS.

Woods, A., Fletcher, P., \& Hughes, A. (1986). Statistics in language studies. Cambridge: Cambridge University Press. 
APPENDIX A

HUMAN SUBJECTS COMMITTEE APPROVAL 


\section{OFFICE OF GRADUATE STUDIES AND RESEARCH}

\section{Research and Sponsored Projects}

DATE: $\quad$ December 2, 1996

TO: $\quad$ Susan Livick $\quad$ SSNḦ: 571-85-0726

FROM: Torvikki Vandiver, Chair, HSRRC, 1996-97 Acquisition in Children with Severe Speech Production Impairments Using Alternative Communication Systems."

Your proposal is exempt from further HSRRC review, and you may proceed with the study.

Even with the exemption above, it was necessary by University policy for you to notify this Committee of the Proposed research and we appreciate your timely attention to this matter. If you make changes in your research protocol, the Committee must be notified. This approval is valid for one year from date of issue.

c: $\quad$ Maureen Orr Eldred

Rhea Paul, Project Advisor 
APPENDIX B

CONSENT FORM 


\section{PORTLAND STATE UNIVERSITY \\ CONSENT FOAM: FOA PARTICIPATING IN A STUDY OF COGNITIUE AND LANGUAGE CHARACTERISTICS OF CHILOAEN WITH SEUERE SPEECH IMPRIRMENTS}

take part in the research conducted by Dr. Rhea Paul on the development of language in children with severe speech production impalrments. I understand that the study Involves gluing stendard tests and cllnical assessments, Including parent intervieus, designed to evaluate the hearing and understanding, vocal ablittes, motor abllities, play, cognitlue, soctal and adaptive skills of young chlldren with severe speech Impairments and compare them to those of normally developing peers. I also understand that the study may Involve uldeotaping me and $\mathrm{my}$ child to look at how mothers interact with chlldren with speech impaliments and compare these interactions to those of mothers with normaliy speaking chlidren. If $\mathrm{my}$ chlld is involued in an intervention program, the study moy also involve videotaping my chlld with the cllnician to look at the way that cliniclons talk to children with severe speech impoirments.

I understand that the study will take several hours of $\mathrm{my}$ and $\mathrm{my}$ chlid's time, some of which will take place in our home, and some may take place in my child's clinicat setting or at PSU. Dr. Paul has told mo that the purpose of the study is to leam more about how children who cannot talk learn to understand and communicate, and that this knowledge can help develop botter ways to teach language skills to these children. I understend thet my chlld may not recelve any direct benefit from partlcipating In the study, however.

Dr. Paul has agreed to answer any questions I have about the study and what I am expected to do. I understand that all information collected about my child in the study will remain conndential to the eutent permitted by law, and that the names of all the people in the study will be kept conflidential. I understand that I do not have to take part in this study, and $m y$ dectsion will not affect any services my chlld recelves. If 1 choose to particlpate, I may withdraw at anyetime.

I have read and understand the above information and agree to allow $\mathrm{my}$ chlld to take part in this study.

Date: Signature:

Please keep one copy of this permission form yourself and return one to Susan. If you bave concerns or questions about the study please contact Dr. Paul at 725-3142 or the Chair of the Human Subjects Research Review Committee, Office of Research and Sponsored Projects, 105 Neuberger Hall, Portland State University, $503 / 725-3417$. 
APPENDIX C

VINELAND ADAPTIVE BEHAVIOR SCALES - INTERVIEW EDITION 


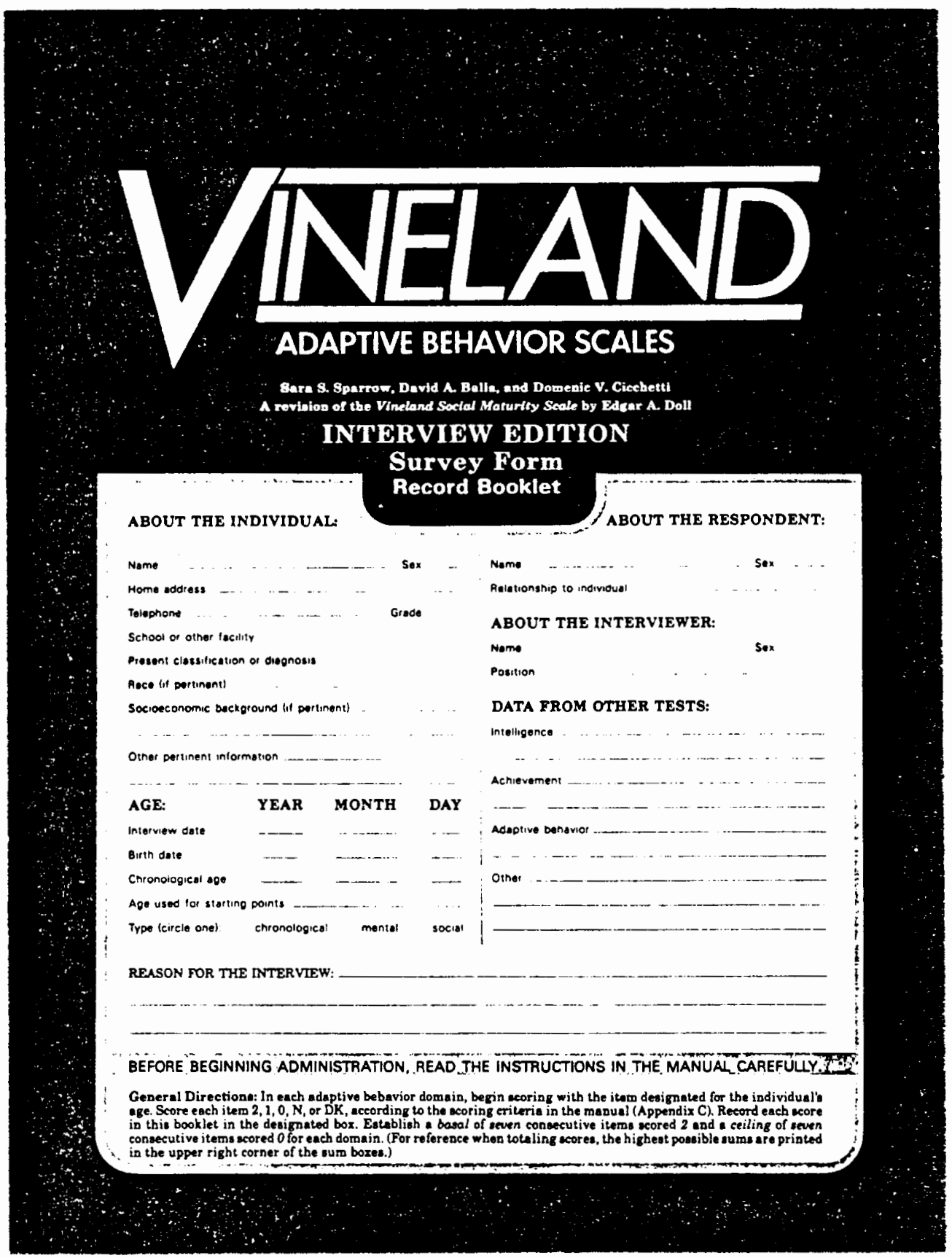




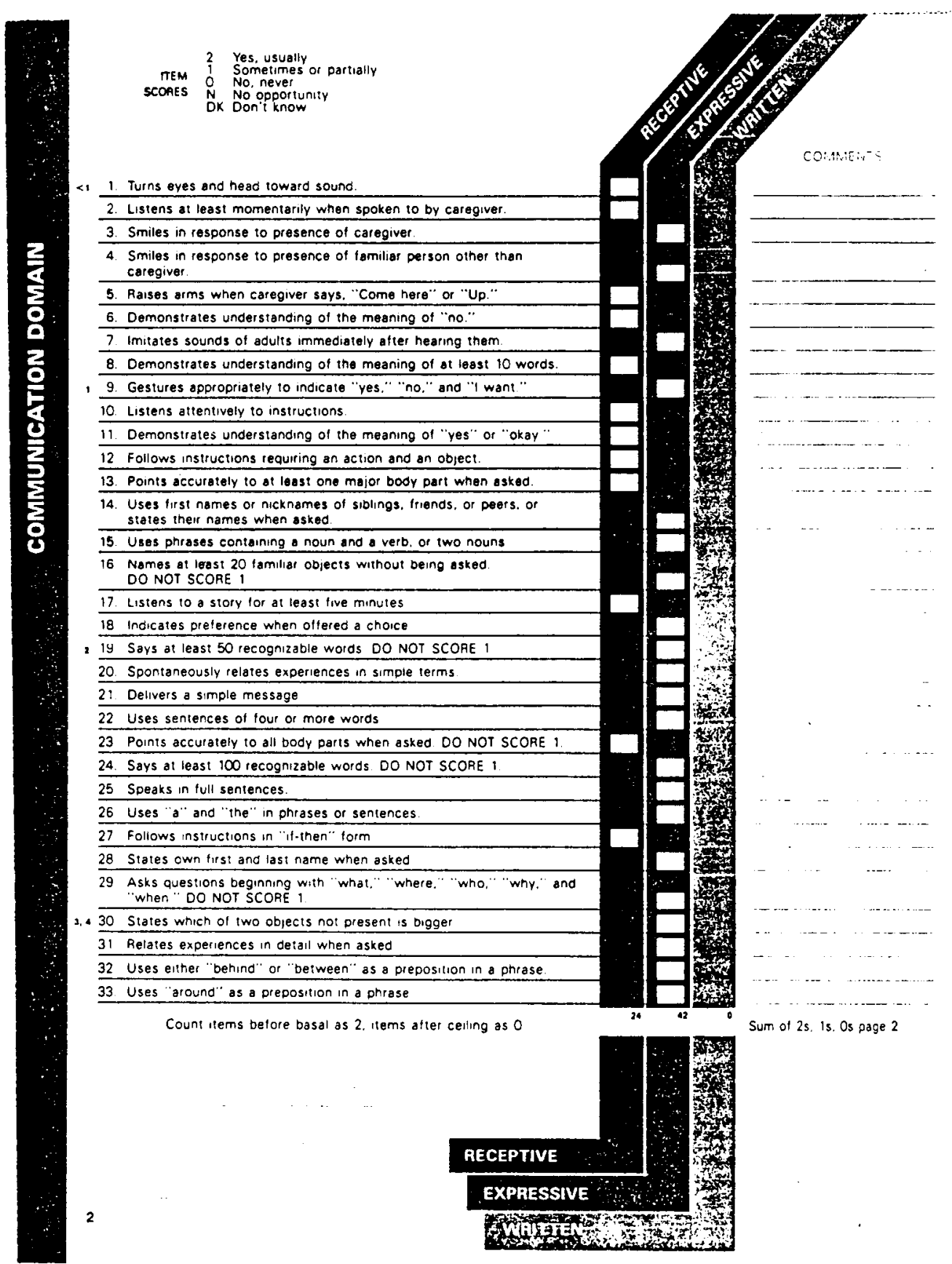


34. Uses phrases or semtences containing "but" and "or" 35. Articulates clearly, without sound substitutions

36. Tells popular story, fairy tale, lengthy joke. or television show piot

- 37. Recites all letters of the alphabet from memory

38. Reads at least three common signs

39. States month and day of birthday when asked.

40. Uses irregular plutals

- 4i. Prints or writes own first and last name

42. States telephone number when asked. N MAY BE SCORED.

43 States complete home addiess. including city and state. when asked

44 Reads at least 10 words silently or aloud

45 Peints of writes at least 10 words from memory

46. Expresses ideas in more than one way. without assistance.

47 Reads simple stories aloud

1. 48 Prints or writes simple sentences of three or four words

49 Attends to school of public lecture more than 15 minutes

50 Reads on own initiative

51 Reads books of st least second.grade level

52 Arranges items or words alphabetically by lirst letter

53 Prints or writes short notes or messages

- 54 Gives complex directions 10 others

55 Writes beginning leiters DO NOT SCORE

56 Reads books of at least lourth-grade level

57 Writes in cursive most of the time DO NOT SCORE 1

10 it 58 Uses a dictionary

59 Uses the table of contents in reading materials

60. Writes teports of compositions DO NOT SCORE

61 Addresses envelopes completely

62. Uses the index in reading materials

63. Reads adult newspaper stories $N$ MAY BE SCORED

64 Has reailstic long-range goals and describes in detall plans to achieve them

65 Writes advanced letters

66. Reads adult newspaper or magazine stories each week N MAY BE SCORED

67 Writes business fetlers DO NOT SCORE

Count tiems betore basal as 2 , thems after celling as 0

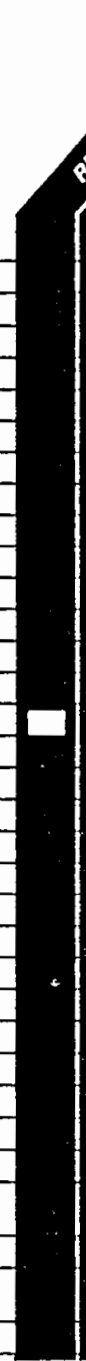

70

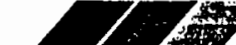

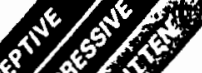

$\%$

$\therefore 3,1 ! v^{\top}$

드.

-

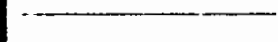

-

-

$\ldots$

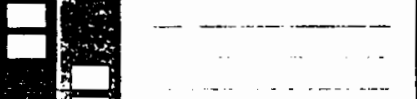

1

ai

$-\cdots$
$\cdots \quad-\cdots$

$+\cdots$

-.......

(.......

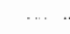

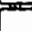

(b)

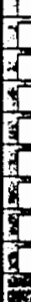

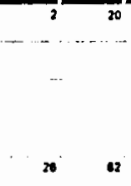

4

Sum of 2s. 1s, Os page 3

Sum of 2s, 1s, Os page 2

Number of Ns pages 2 and 3

Number of OKs pages 2 ano 3

in

SUBdomaIN RAW SCORE

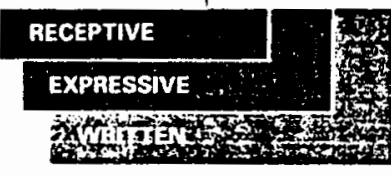




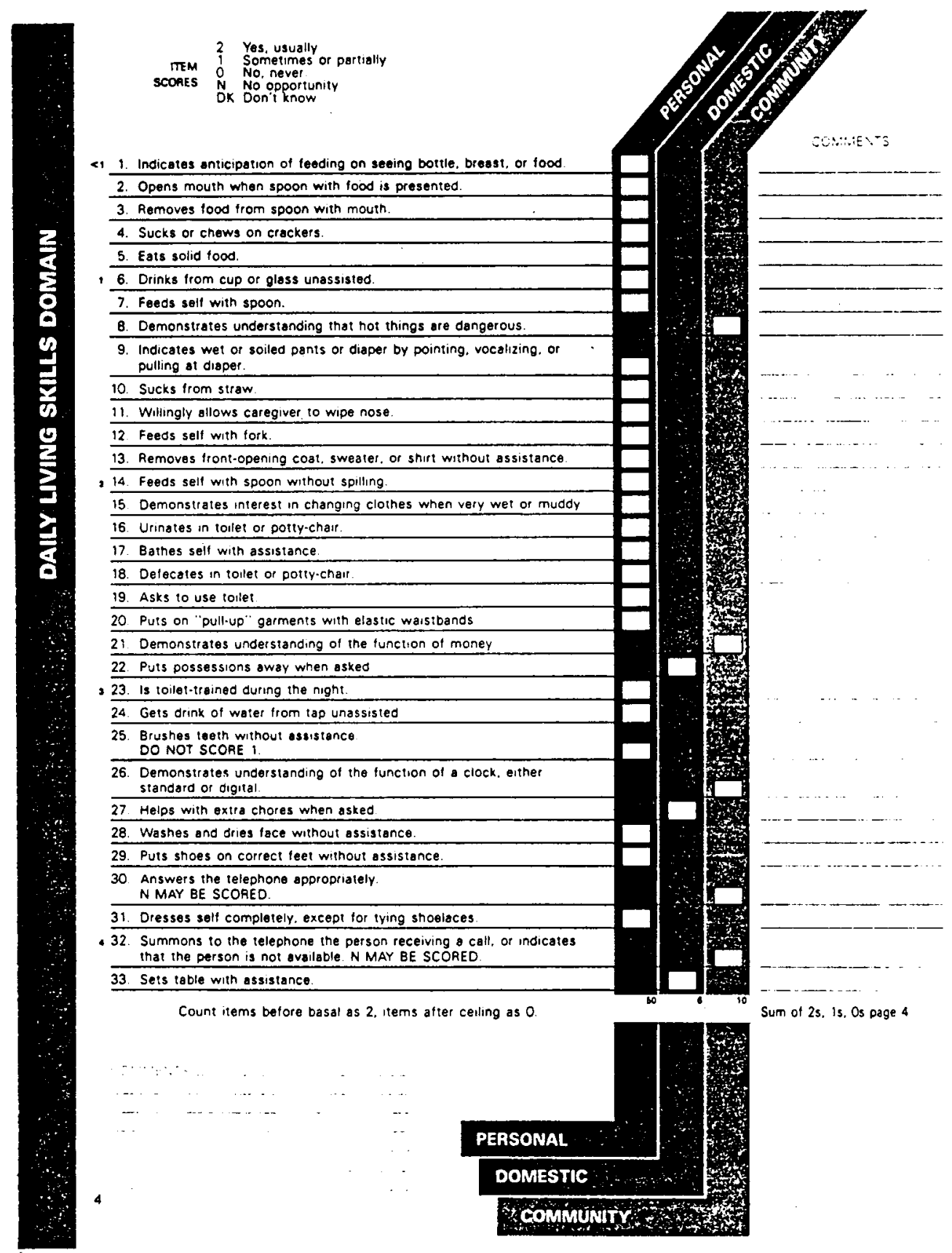




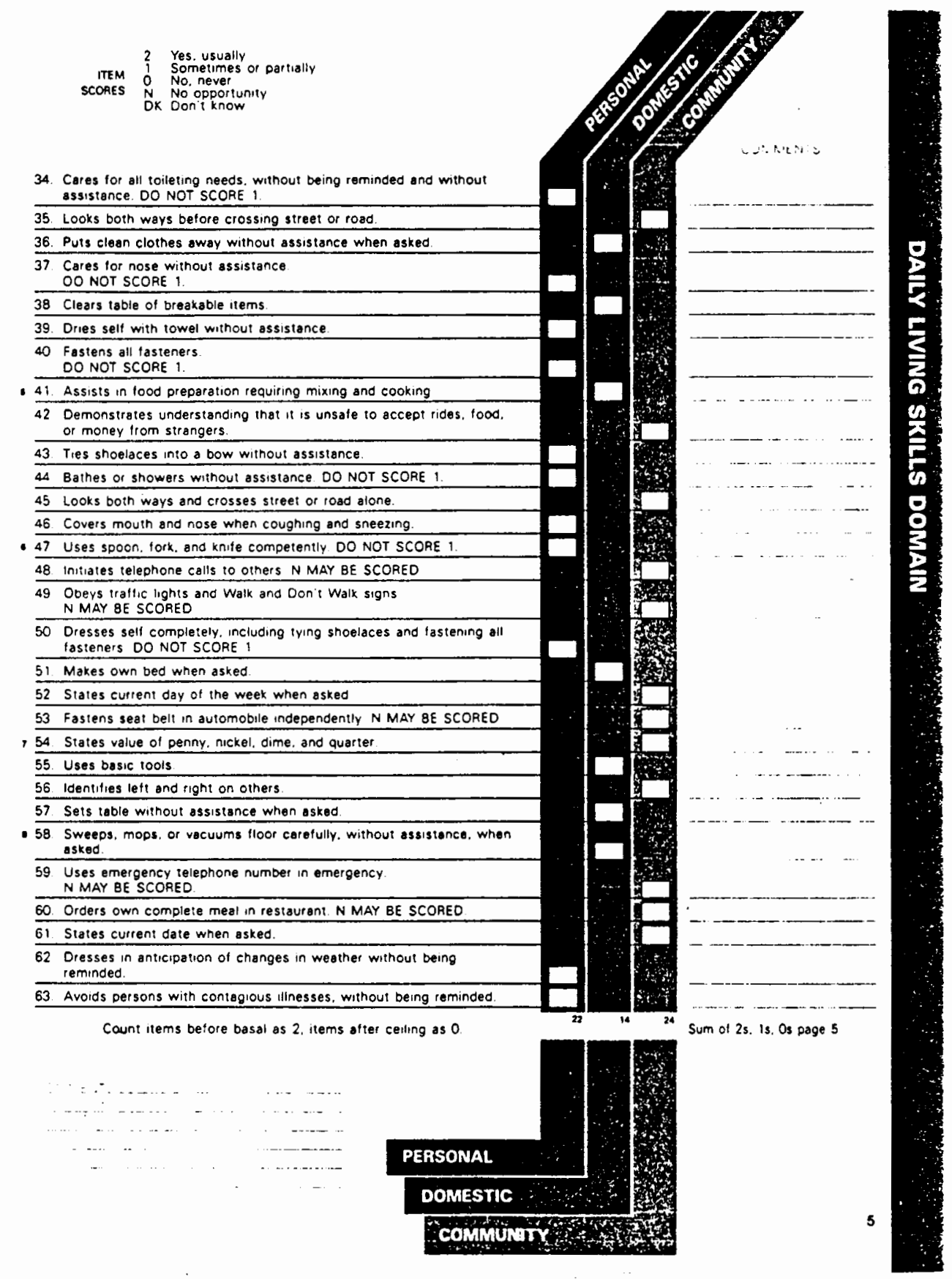




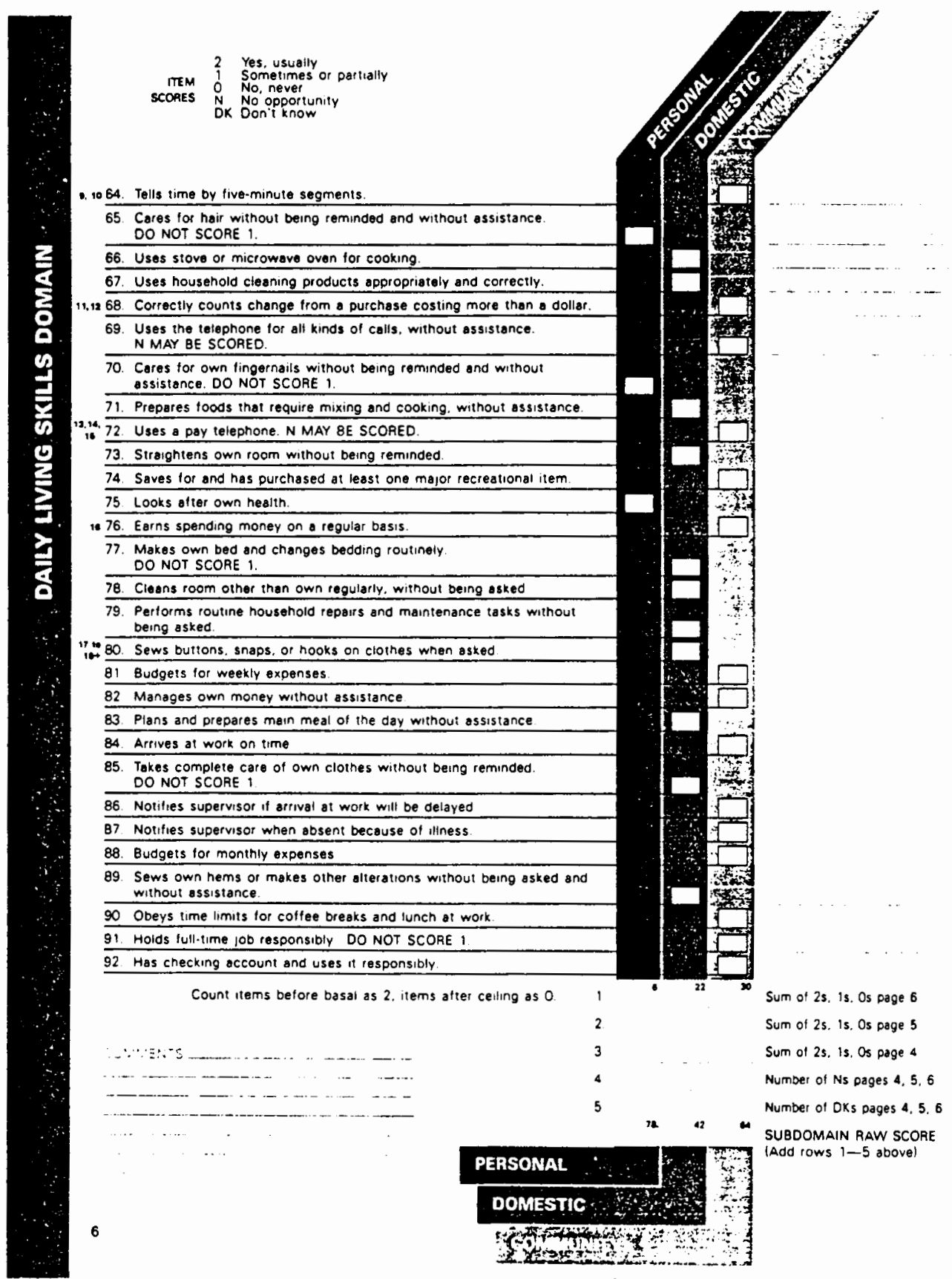




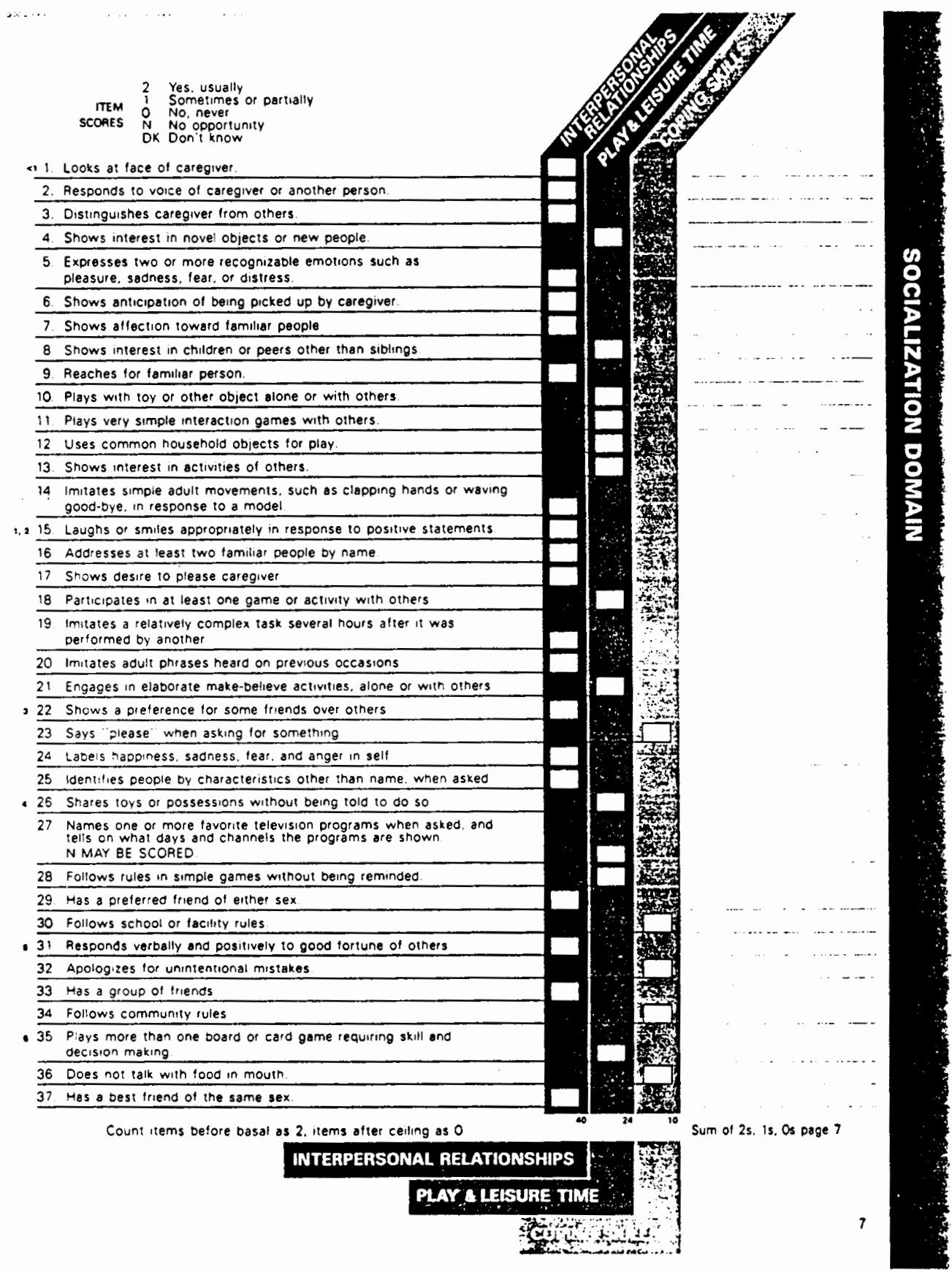




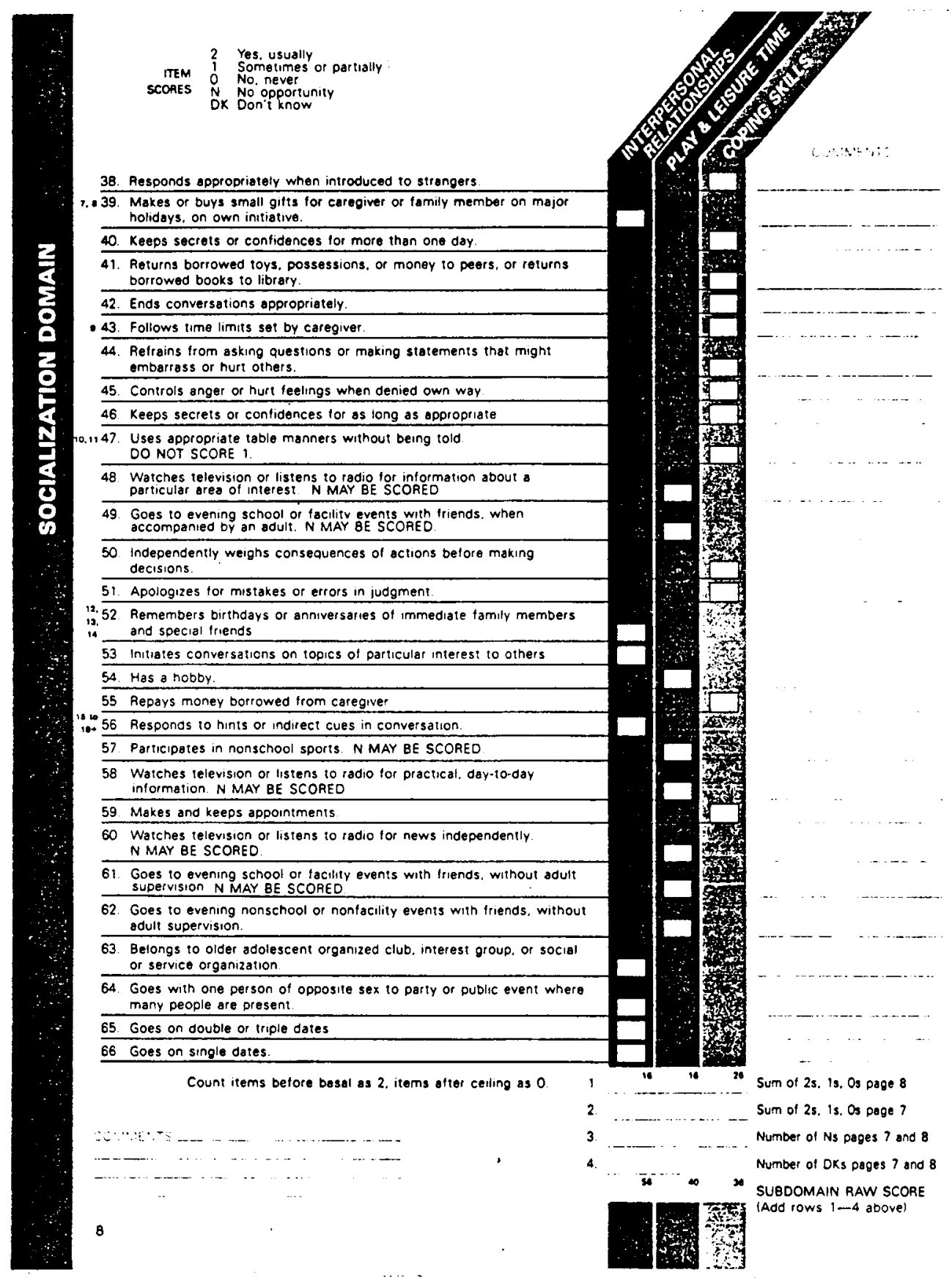




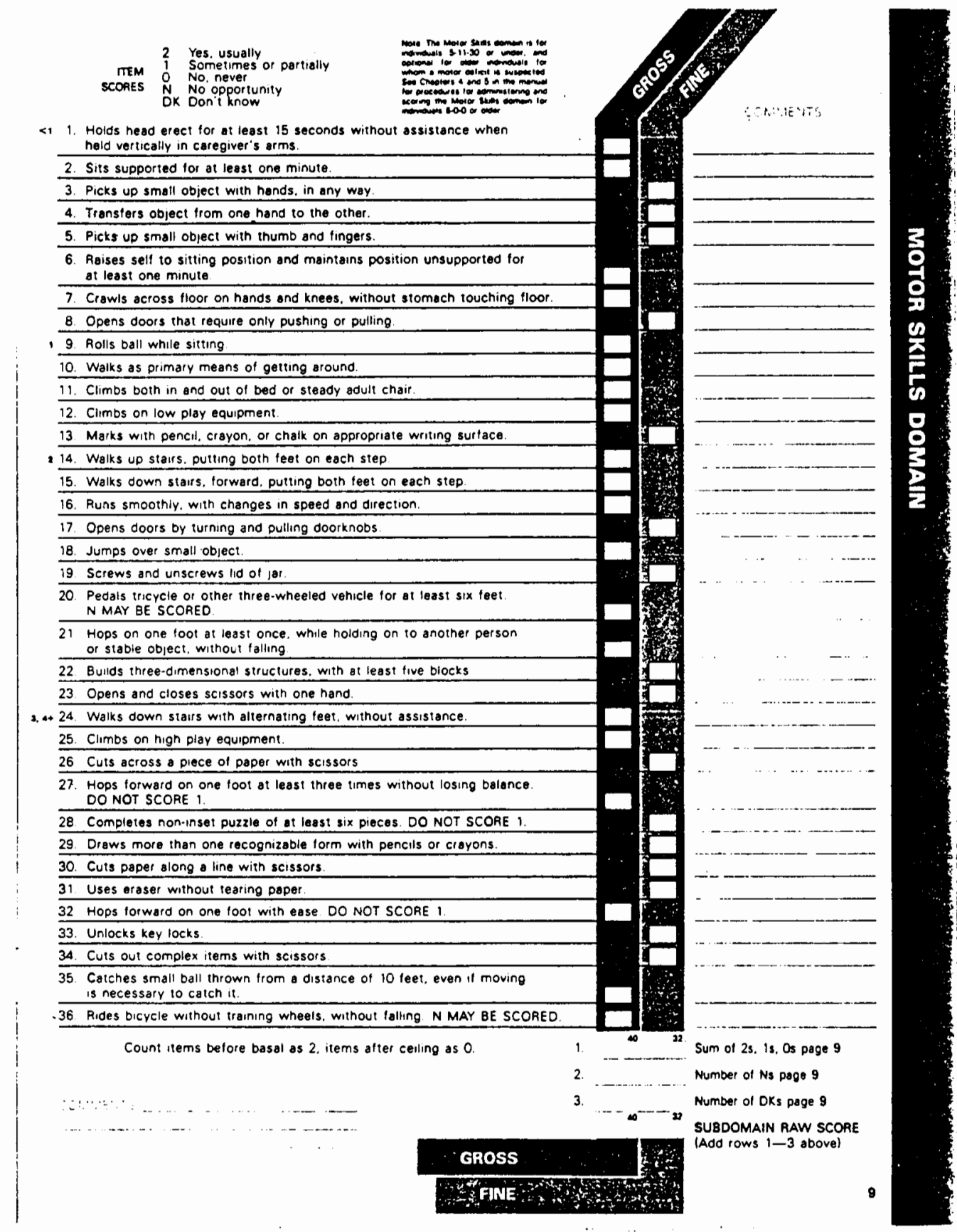




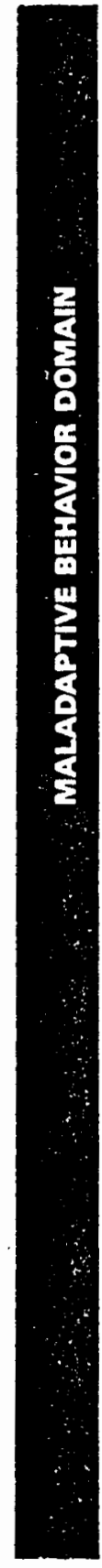

Note: The Moladaptive Behavior domsin is for individuals $5-0-0$ or older. Administretion is optional.

\section{TEM SCONES}

2 Yos, usualily DO NOT SCOAE N OA DK.

\section{PART 1}

1. Sucks thumb or fingers.

2. Is overly dependent.

7. Bites fingernails.

8 Avoids school or work.

9. Exhibits extreme anxiety.

10. Exhibits tics.

11. Cries or laughs too easily.

12. Has poor eye contect.

13. Exhibits excessive unhappiness.

14. Grinds teeth during day or night.

15. is too impulsive.

16. Has poor concentration and attention

17. is overly active.

18. Has temper :antrums

19. Is negativistic or defiant

20. Taases or bulties.

21 Shows lack of consideration

22. Lies. cheats, or stesls.

23. is 100 physicalty eggressive.

24. Sweers in ineppropriate stuations.

25. Runs away.

26. is stubborn or sullen.

27. Is truant from sehool or work.

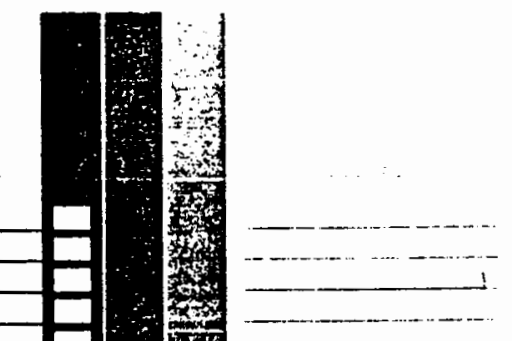

\section{A. PART I RAW SCORE}

PART 2

Note: Part 2 is for individuals who will be compared only with supplementsery norm groups.

28. Engoges in ineppropriate sexual behavior

29. Has excessive of peculiar preoccupetions with objects of activities. 30. Expresses thoughts that are not sensible.

31. Exhibits extremely peculiar mannerisms or habits

32. Displays behaviors that are self-injurious.

33 Intentionally destroys own or another's property

34 Uses bizarie speech.

35. Is unawgre of what is happening in immediate surroundings

36. Rocks back and forth when sitting or stonding

B. Sum of 2s, 1s, Os Part 2 PAATS 1 AND 2 RAW SCORE uad $A$ and Bi 
ABOUT THE INTERVIEW:

Responctent's estimate of the individual's functioning

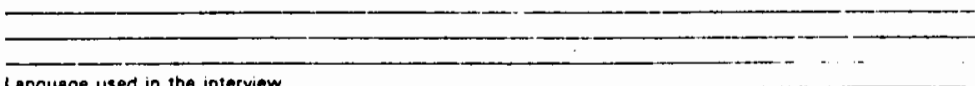

Language used in the interview

Special characteristics of the individual

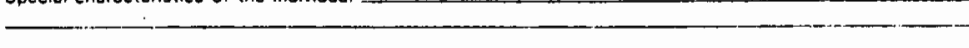

-

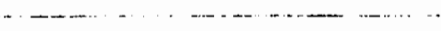

Estimate of repport established with the respondent

-

-

Estimste of the respondent's accuracy

General obseivations 
Vineland Adaptive Behavior Scales: INTERVIEW EDITION Survey Form Indrioual is name

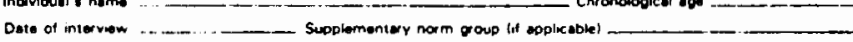
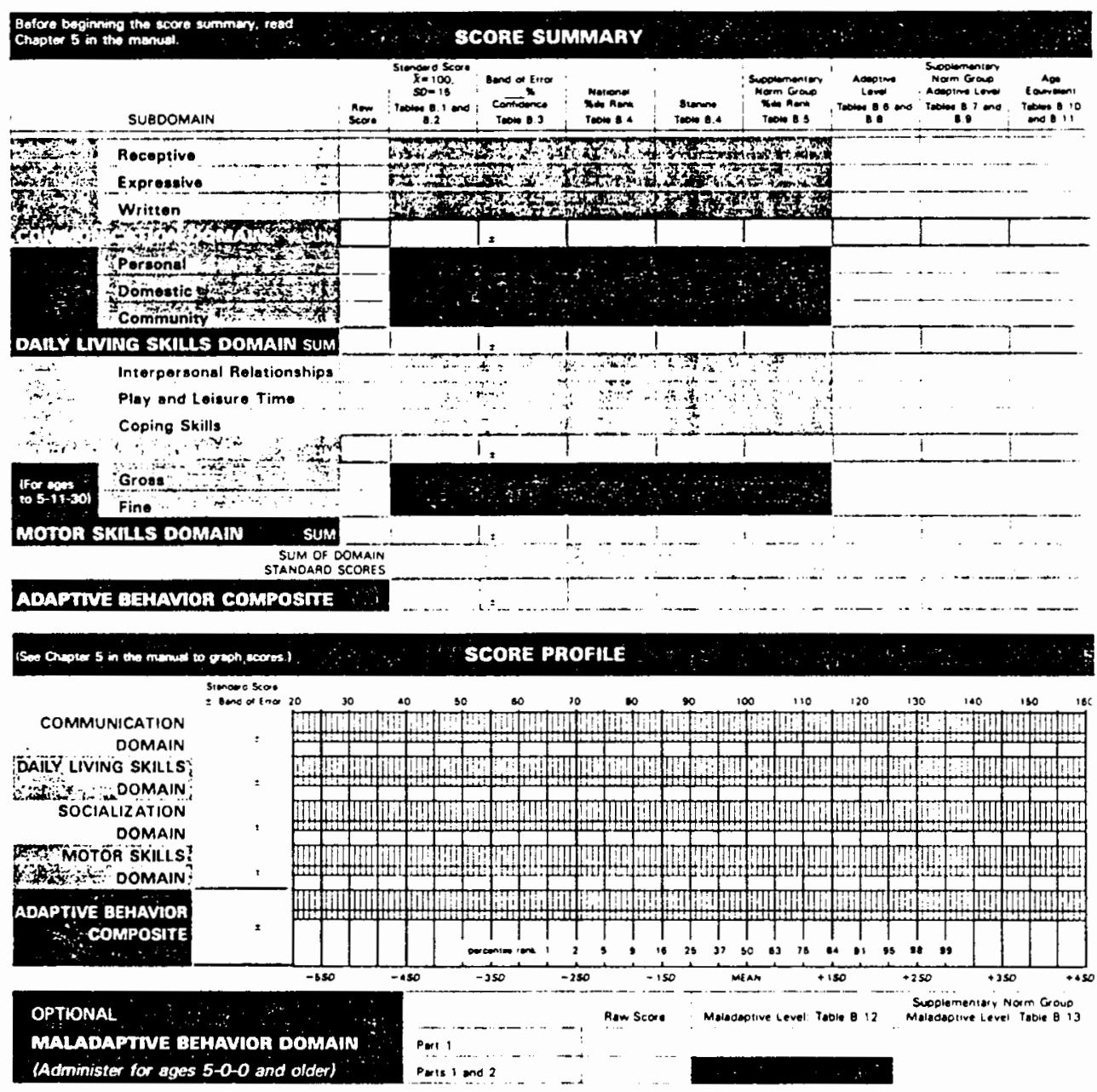

Adationa inlepretive intormation isee Chaptets 5 and 6 in the inanual 


\section{APPENDIX D}

PEABODY PICTURE VOCABULARY TEST - REVISED, FORM L 


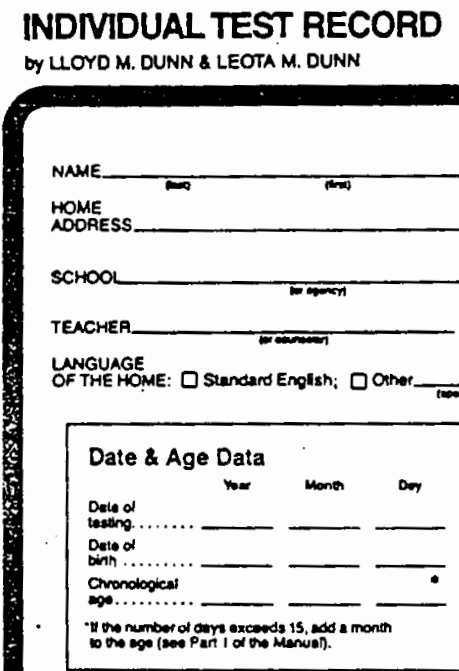

\section{FORM L}

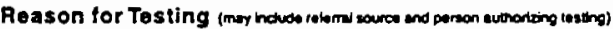

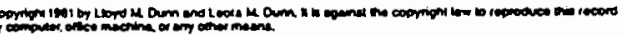

AGS Published by American Guidance Semico, inc., 4201 Woodland Hoed, Cirdo Pires, Minnesota 55014-1796; tod tree 800-328-2560. For additional forms, call or writle and ask lor item 2002 (25 per packago) 


FORM L] TEST ITEMS AND
ABBREVIATED INSTRUCTIONS

\begin{tabular}{|c|c|c|}
\hline & & \\
\hline 44 & dripping. . & \\
\hline 45 & claw ......... (4) & - \\
\hline .46 & decorated ..... (3) & - \\
\hline 47 & trame $\ldots \ldots \ldots$ (1) & - \\
\hline 48 & torest......... (3) & \\
\hline 49 & faucet ........ (2) & _. \\
\hline 50 & group $\ldots \ldots \ldots$ (3) & _. \\
\hline 51 & stem ......... (3) & $\ldots$ \\
\hline 52 & vase $\ldots \ldots \ldots$ (3) & \\
\hline 53 & pedal. ......... (i) & - \\
\hline 54 & capsute........ (2) & $\ldots$ \\
\hline 55 & surprised. ..... (4) & \\
\hline 56 & bark......... (2) & \\
\hline 57 & mechanic ..... . (2) & 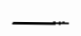 \\
\hline 58 & tambourine .....(1) & \\
\hline 59 & ofsappointment . (4) & \\
\hline 60 & awarding. ...... (3) & \\
\hline 61 & pitcher....... . (3) & 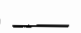 \\
\hline 62 & reel . . . . . . . . (1) & - \\
\hline 63 & signal... & \\
\hline 64 & trunk... & \\
\hline & human........ (2) & \\
\hline 66 & nostrit ........ (1) & \\
\hline 67 & disagreement. . (1) & -1 \\
\hline 68 & exhausted..... (2) & \\
\hline 69 & vine........... (4) & - \\
\hline & ceremony. & \\
\hline 71 & casserole... & \\
\hline 72 & vehicte ....... (4) & \\
\hline 73 & globe........... (3) & \\
\hline 74 & fliling .. & \\
\hline 75 & clamp $\ldots \ldots \ldots$ (2) & $\ldots$ \\
\hline 76 & reptile ......... (2) & ـ- \\
\hline 77 & island ...... & \\
\hline
\end{tabular}




\begin{tabular}{|c|c|c|c|c|c|c|c|c|c|c|c|}
\hline$\approx$ & $=$ & - & $m$ & $\equiv$ & $=$ & سي & $=$ & $\equiv$ & $m$ & & \\
\hline 78 & spaluda. & - & 0 & 112 & fusk & $-\ldots$ & 0 & 146 & nautical.. & & 5 \\
\hline 79 & cooperation.... (4) & $\ldots$ & $\square$ & 113 & Utensit. & $\ldots$ & 0 & 147 & tangent. . & & \\
\hline (j) $\mathrm{BO}$ & scalp........ (4) & & $\Delta$ & 114 & citrus. . & - & 다 & 148 & inclement ..... (4) & & \\
\hline 81 & $\ldots$ (2) & $\ldots$ & $\Omega$ & 115 & pedestrian..... (2) & $\ldots$ & $\Delta$ & 149 & trajsctory........(1) & & $\square$ \\
\hline 82 & $\ldots$ (2) & & 0 & 116 & parallelogram...(1) & - & $\Omega$ & 150 & tettered....... (1) & & $\Delta$ \\
\hline 83 & demolishing ... (4) & — & $\Delta$ & 117 & slumbering . . . . (3) & - & 0 & 151 & waif..... & & \\
\hline 84 & balcony....... (1) & & 0 & 118 & peninsula ..... (4) & 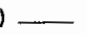 & $\hat{4}$ & 152 & jubilant ........ (2) & & \\
\hline (i) 85 & $\ldots$ (1) & & 0 & 119 & uphoistery..... (2) & 1 & 0 & 153 & pillering....... (4) & & 战 \\
\hline 86 & amazed. & & $\square$ & 120 & barricade...... (4) & i & 0 & 154 & repose........ (2) & & 0 \\
\hline 87 & fubular... & & $\Delta$ & 121 & quartet $\ldots \ldots$ (4) & & $\square$ & 155 & carrion......... (3) & & 0 \\
\hline 88 & tusk.......... (1) & & $\Omega$ & 122 & tranquil ... & & $\Delta$ & 156 & indigent....... (2) & & \\
\hline 89 & $\ldots$ (3) & & 0 & 123 & abrasive . . & - & $\Omega$ & 157 & convex ........ (1) & & $\Delta$ \\
\hline (i) 90 & communication. (4) & & 胡 & 124 & latigued....... . (3) & 1. & 0 & 158 & ernaciated..... (2) & & $\Omega$ \\
\hline 91 & carpenter ...... (2) & & 0 & 125 & spherical..... (2) & & Н & 159 & divergence $\ldots .$. (4) & & \\
\hline 92 & Isolation... & & 0 & 126 & syringe .. & & 0 & 160 & dromedary .... (2) & & 亩 \\
\hline 93 & $\ldots$ (3) & & $\square$ & 127 & Veline. . . . . . . (2) & & $\mathrm{O}$ & 161 & embellishing ... (2) & & $\diamond$ \\
\hline 94 & $\ldots$...(3) & & $\Delta$ & 128 & arid......... (4) & ). & $\square$ & 162 & entomologist... . (3) & & 0 \\
\hline (i) 95 & adjustabre ...... (2) & & $\Omega$ & 129 & exterior ....... (1) & i. & $\Delta$ & 163 & constrain ....... (1) & & $\square$ \\
\hline 96 & iragile $\ldots \ldots \ldots$ (3) & & 0 & 130 & constaflation... (4) & & $\Omega$ & 164 & infirm......... (1) & & $\Delta$ \\
\hline 97 & ...(1) & & \& & 131 & cornea........ (2) & ). & 0 & 165 & anthropoid. .... (3) & & $\Omega$ \\
\hline 98 & applianco & - & 0 & 132 & mercantile..... (1) & ) & 出 & 166 & specter . . . . . (4) & & \\
\hline 99 & pyramid. . & & 0 & 133 & ascending...... (3) & & 0 & 167 & incertitude.... . (2) & & 它 \\
\hline 100 & $\ldots(1)$ & & $\square$ & 134 & Giltralion........ (1) & & 0 & 168 & vitreous.... & & 0 \\
\hline 101 & ....(1) & & $\Delta$ & 135 & consuming .... (4) & & $\square$ & 169 & obelisk .... & & 0 \\
\hline 102 & $\ldots \ldots$ (4) & 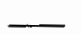 & $\Omega$ & 136 & cascade ...... (4) & 1 & $\Delta$ & 170 & embossed..... (4) & & $\square$ \\
\hline 103 & lecturing. & & 0 & 137 & perpendicular .. (3) & 3 & $\Omega$ & 171 & ambulation ... . (2) & & $\Delta$ \\
\hline 104 & $\ldots$ (4) & & 它 & 138 & replenishing .... (1) & & 0 & 172 & calyx .........(2) & & $\Omega$ \\
\hline (i) 105 & contemplating . . (2) & & 0 & 139 & emission....... (3) & & 的 & 173 & osculation...... (3) & & \\
\hline 106 & canister... & - & 0 & 140 & talon . . . . . . (3) & ) & 0 & 174 & cupola........ (4) & & 亩 \\
\hline 107 & dissecting . . . . . (3) & & $\square$ & 141 & wrath......... (3) & & 0 & 175 & homunculus .... (4) & & \\
\hline 108 & link ......... (4) & & $\Delta$ & 142 & incandescent .. (4) & 1 & $\square$ & & Jating Paw Score & & \\
\hline 109 & solemn & & $\mathbf{\Omega}$ & 143 & arrogant ....... (2) & & $\Delta$ & & & & \\
\hline (3) 110 & archery. & & 0 & 144 & confiding . ...... (3) & & $\boldsymbol{\Omega}$ & & & & \\
\hline 111 & transparent .... (3) & & $\Delta$ & 145 & rhombus ...... (3) & & 0 & & & & \\
\hline
\end{tabular}




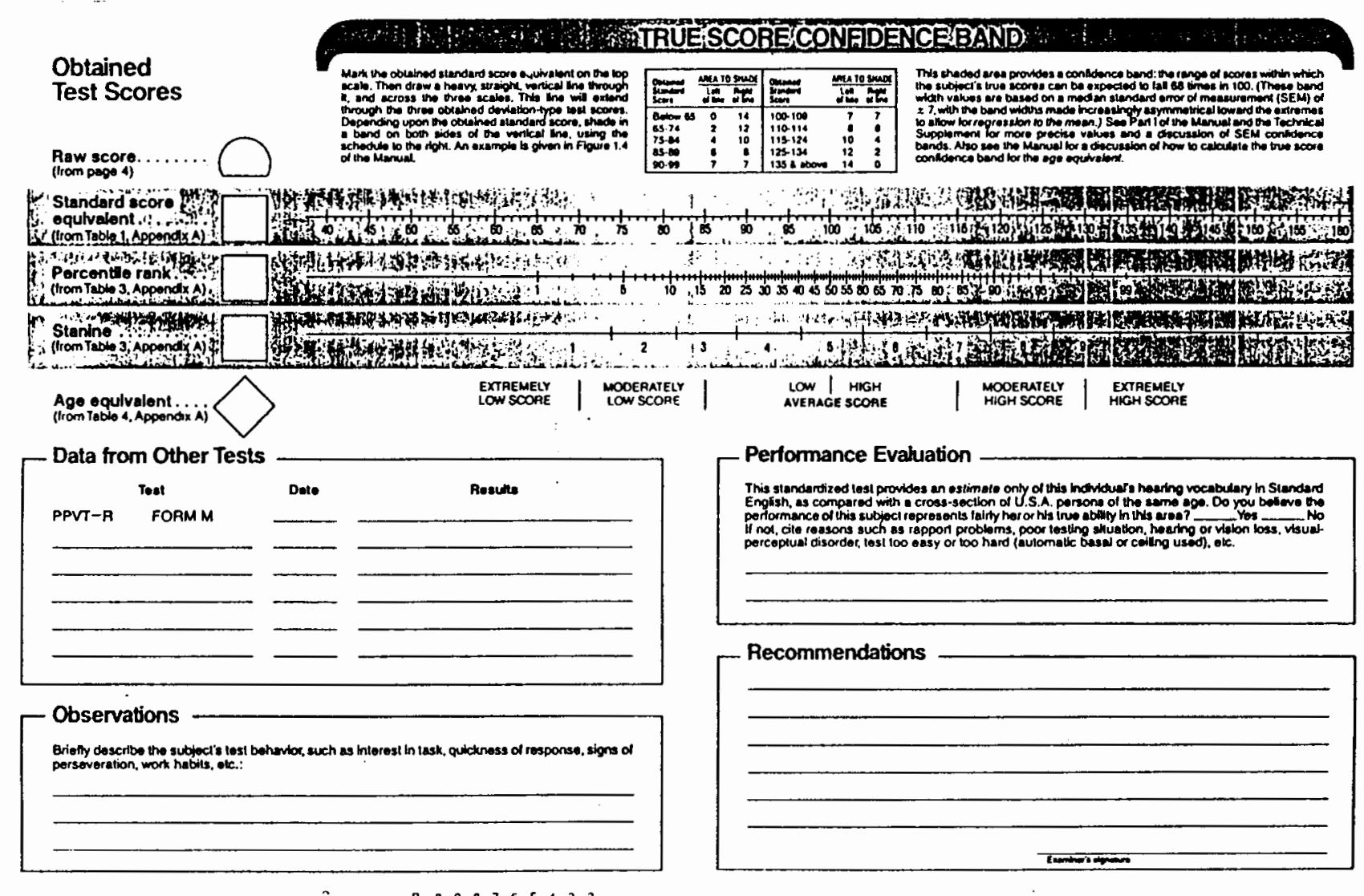




\section{APPENDIX E}

PEABODY PICTURE VOCABULARY TEST- REVISED SIZE MODIFICATIONS 


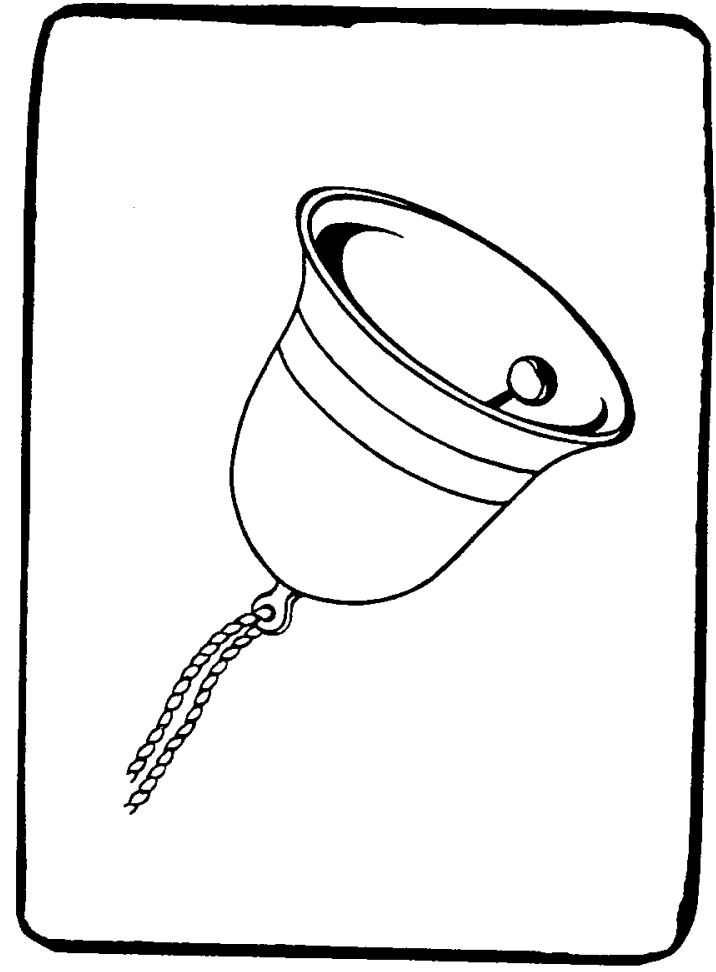




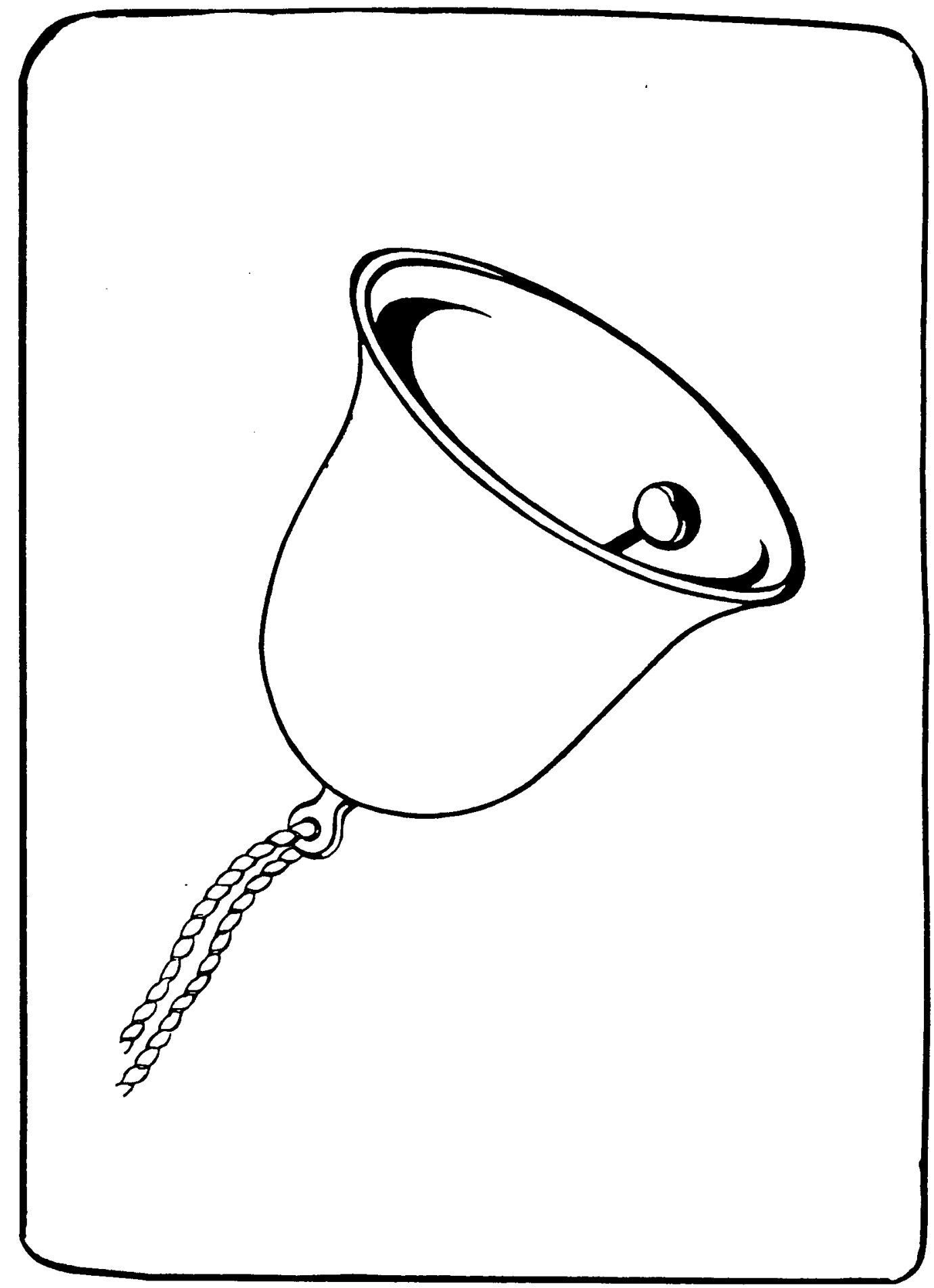




\section{APPENDIX F}

RAW DATA TABLE 


\begin{tabular}{|c|c|c|c|c|c|c|c|c|c|c|c|c|c|c|c|}
\hline SUBJ & $A G E$ & GENDER & GROUP & PPVT SS & PPVT AE & REC AE & EXP AE & COMM SS & DL SS & SOC SS & GMAE & $\mathrm{FMAE}$ & MOT SS & MOT AE & COMP SS \\
\hline 1 & 44 & male & severe & 79 & 33 & 30 & 18 & 63 & 52 & 79 & 6 & 7 & 30 & 7 & 50 \\
\hline 2 & 56 & female & moderate & 79 & 42 & 47 & 25 & 67 & 54 & 74 & 23 & 18 & 48 & 21 & 56 \\
\hline 3 & 68 & male & mild & 84 & 54 & 47 & 31 & 61 & 87 & 90 & 72 & 72 & 115 & 55 & 84 \\
\hline 4 & 62 & male & moderate & 39 & 27 & 47 & 23 & 56 & 45 & 63 & 20 & 20 & 38 & 19 & 47 \\
\hline 5 & 37 & female & severe & 75 & 26 & 22 & 14 & 64 & 50 & 63 & 4 & 4 & 36 & 3 & 49 \\
\hline 6 & 37 & male & moderate & 108 & 41 & 47 & 39 & 108 & 72 & 103 & 14 & 14 & 52 & 14 & 78 \\
\hline 7 & 52 & male & moderate & 98 & 50 & 47 & 48 & 100 & 72 & 107 & 13 & 28 & 45 & 17 & 75 \\
\hline 8 & 72 & male & severe & 73 & 49 & 22 & 14 & 44 & 25 & 52 & 4 & 4 & 19 & 3 & 32 \\
\hline 9 & 68 & female & mild & 82 & 50 & 47 & 34 & 65 & 70 & 86 & 33 & 62 & 70 & 46 & 67 \\
\hline 10 & 50 & male & severe & 39 & 23 & 21 & 14 & 55 & 53 & 73 & 29 & 24 & 58 & 28 & 55 \\
\hline 11 & 47 & female & moderate & 57 & 27 & 18 & 16 & 57 & 51 & 67 & 20 & 18 & 50 & 19 & 52 \\
\hline 12 & 62 & male & moderate & 59 & 36 & 26 & 23 & 55 & 44 & 79 & 11 & 36 & 38 & 19 & 50 \\
\hline 13 & 41 & female & moderate & 81 & 30 & 30 & 21 & 70 & 56 & 73 & 22 & 36 & 67 & 28 & 61 \\
\hline 14 & 71 & male & severe & 40 & 30 & 18 & 11 & 43 & 24 & 52 & 9 & 6 & 19 & 8 & 27 \\
\hline 15 & 43 & male & severe & 56 & 26 & 22 & 16 & 60 & 51 & 52 & 4 & 8 & 28 & 6 & 44 \\
\hline
\end{tabular}

$\mathrm{AE}$ - age equivalent

SS - standard score

REC - VABS receptive communication

EXP - VABS expressive communication

COMM - VABS communication skills domain
DL - VABS daily living skills domain

SOC - VABS socialization skills domain

GM - VABS gross motor

FM - VABS fine motor

MOT - VABS motor skills domain

COMP - VABS composite 